\title{
DISTRIBUIÇÃO DA AFLATOXINA EM FRAÇÕES DE MILHO CONTAMINADO OBTIDAS APÓS SEPARAÇÃO GRANULOMÉTRICA E VISUAL
}

\section{FABIANA SEGATTI PIEDADE}

Engenheira Agrônoma

Orientador: Prof. Dr. HOMERO FONSECA

\begin{abstract}
Dissertação apresentada à Escola Superior de Agricultura "Luiz de Queiroz", Universidade de São Paulo, para obtenção do título de Mestre em Agronomia, Área de Concentração: Ciência e Tecnologia de Alimentos
\end{abstract}

PIRACICABA

Estado de São Paulo - Brasil

Fevereiro - 2001 
Dados Internacionais de Catalogação na Publicação (CIP) DIVISÃo DE BIBLIOTECA E DOCUMENTAÇÃO - Campus "Luiz de Queiroz"/USP

\author{
Piedade, Fabiana Segatti \\ Distribuição da aflatoxina em frações de milho contaminado obtidas após separação \\ granulométrica e visual / Fabiana Segatti Piedade. - - Piracicaba, 2001. \\ $62 \mathrm{p}$.
}

Dissertação (mestrado) - - Escola Superior de Agricultura Luiz de Queiroz, 2001. Bibliografía.

1. Aflatoxina 2. Contaminação de alimento 3. Distribuição 4. Micotoxina 5. Microbiologia de alimento 6. Milho 7. Toxicologia de alimento I. Título

CDD 615.95292 


\section{ERRATA}

PIEDADE, FABIANA SEGATTI. Distribuição da aflatoxina em frações de milho contaminado obtidas após separação granulométrica e visual.

\begin{tabular}{|c|c|c|c|c|}
\hline$p$ & item & linha & onde se lê & leia-se \\
\hline ix & Resumo & primeira & $\begin{array}{l}\text { Distribuição da } \\
\text { contaminação com } \\
\text { da aflatoxina }\end{array}$ & $\begin{array}{l}\text { Distribuição } \\
\text { da aflatoxina }\end{array}$ \\
\hline 6 & 3.1 .1 & $\begin{array}{l}\text { décima } \\
\text { terceira }\end{array}$ & Moss\&Smith & Smith\&Moss \\
\hline 7 & 3.1 .1 & quarta & Turmo et al. (1991) & Turmo (1991) \\
\hline 7 & 3.1 .1 & $\begin{array}{l}\text { décima } \\
\text { sexta }\end{array}$ & Maxuitenko & Maxitenko \\
\hline 8 & 3.1 .2 & terceira & Heathcote, 1978 & Heathcote, 1984 \\
\hline 39 & 5.2 & quinta & ...Entretanto, outros & $\begin{array}{l}\text { eliminar esse } \\
\text { período }\end{array}$ \\
\hline 47 & 6 & quinta & ...Entretanto, outros & $\begin{array}{l}\text { eliminar esse } \\
\text { período }\end{array}$ \\
\hline
\end{tabular}


Aos meus pais, Jomar e Marina; Ao meu marido, Marcelo; Aos meus filhos, Matheus e Maria Beatriz - DEDICO - 


\section{Agradecimentos}

- Ao professor Dr. Homero Fonseca pela valiosa orientação, bem como pelo carinho e incentivo a mim dedicados.

- Aos professores do Departamento de Agroindústria, Alimentos e Nutrição pela amizade e colaboração em minha formação profissional

- Aos Engenheiros Agrônomos Eduardo Micotti da Glória e Maria Antônia Calori Domingues pela preciosa colaboração e apoio amigo.

- À biomédica Ivani Valarini Zambelo pela amizade e auxílio.

- À Fundação de Amparo à Pesquisa no Estado de São Paulo pelo auxílio financeiro necessário para a realização desta pesquisa.

- À VEGA - Armazéns Gerais, pela coleta das amostras.

- Ao Prof. Dr. Décio Barbin pela definição da metodologia estatística e à Prof. Dr. e Sônia Maria de Stefano Piedade pela orientação e revisão da análise estatística.

- À bibliotecária Beatriz Helena Giongo pela atenção dedicada à revisão da bibliografia.

- Aos meus pais Jomar e Marina, às minhas irmãs Luciana e Giovana e ao meu irmão Luiz David pelo carinho e dedicação em todos os momentos. 
- Ao meu marido Marcelo e aos meus filhos Matheus e Maria Beatriz pelo carinho e compreensão.

- À todas as pessoas e entidades que direta e indiretamente colaboraram para a realização desta pesquisa. 


\section{SUMÁRIO}

Página

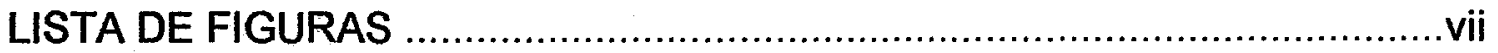

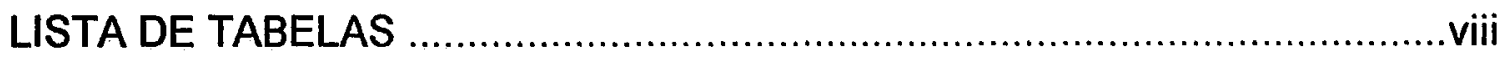

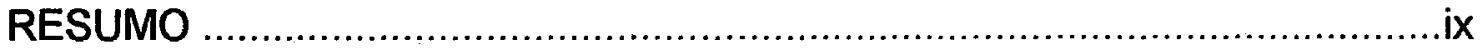

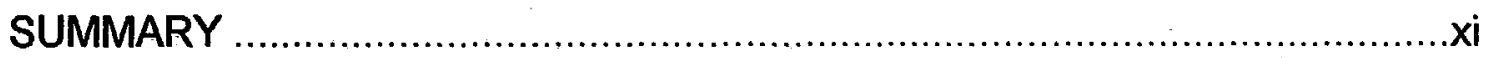

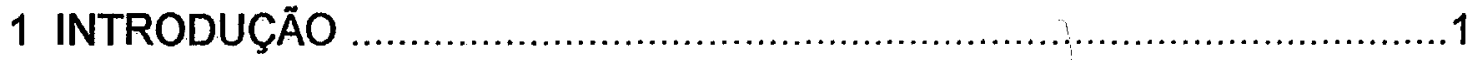

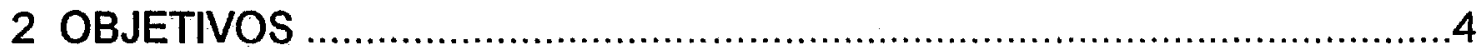

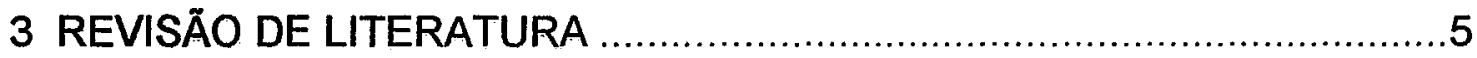

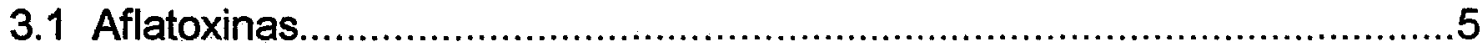

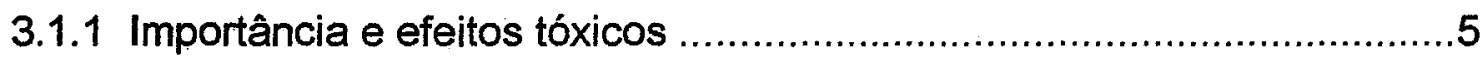

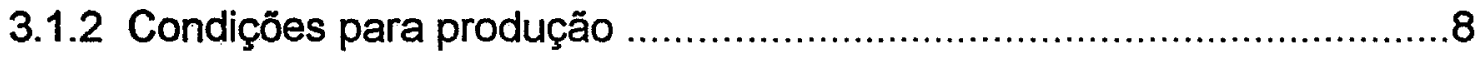

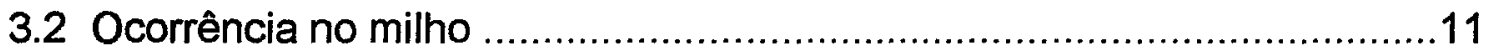

3.3 Distribuição das aflatoxinas nas frações de milho .................................14

3.3.1 Separação granulométrica de impurezas e material estranho ...........14

3.3.2 Separação visual de grãos quebrados, danificados, com alterações na coloração e aparentemente sadios..........................................16

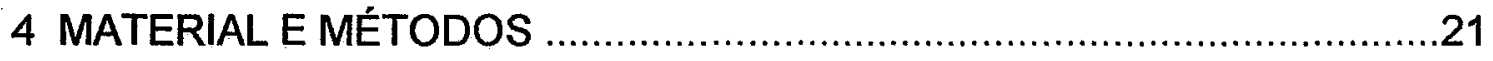

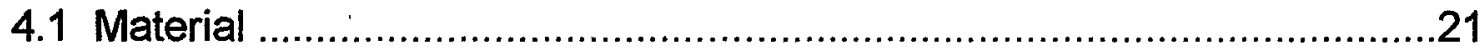

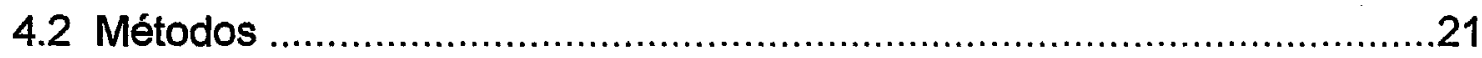

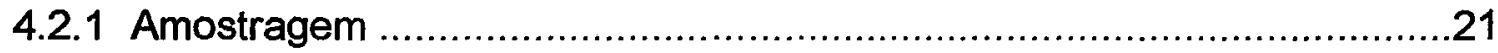

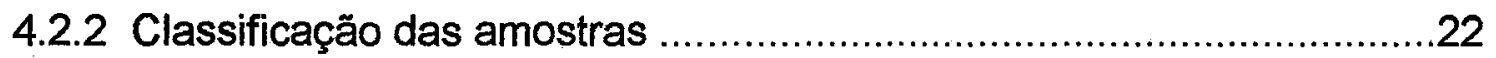

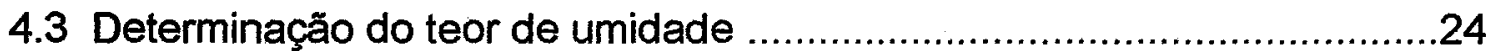

4.4 Avaliação da distribuição com aflatoxinas nas frações granulométricas

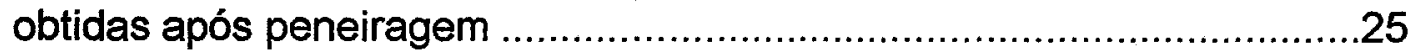

4.5 Avaliação da distribuição da contaminação com aflatoxinas em grãos

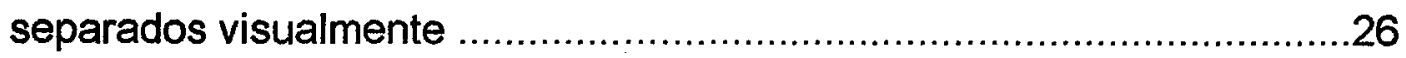

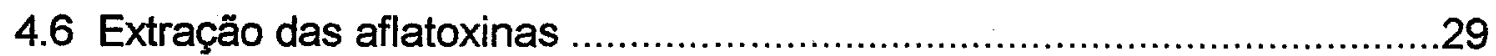

4.6.1 Para a fração maior que $4,5 \mathrm{~mm}$, grãos sadios e não sadios ..............29 


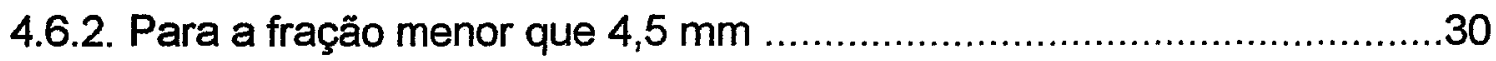

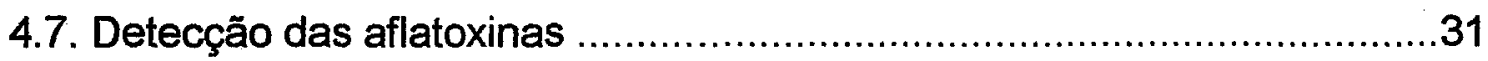

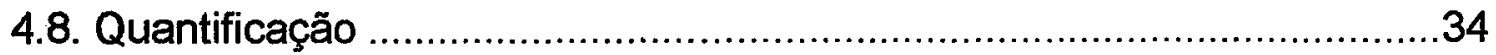

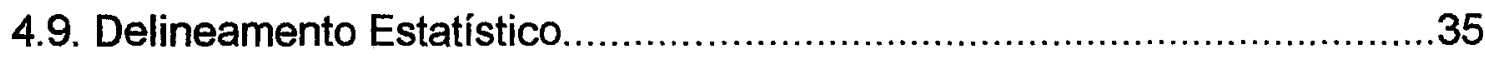

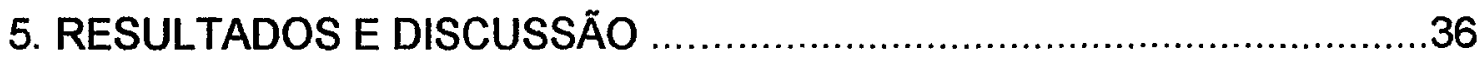

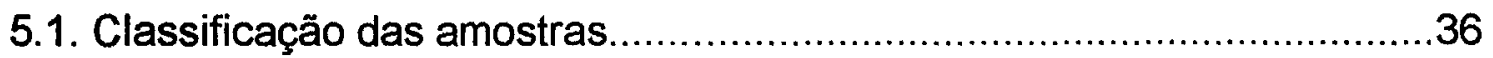

5.2. Distribuição da contaminação com aflatoxinas nas frações separadas

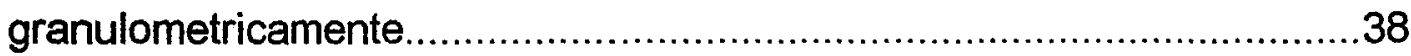

5.3. Distribuição da contaminação com aflatoxinas nas frações separadas

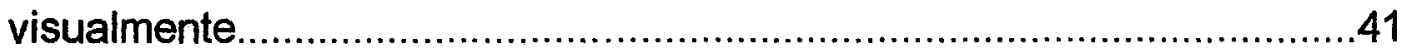

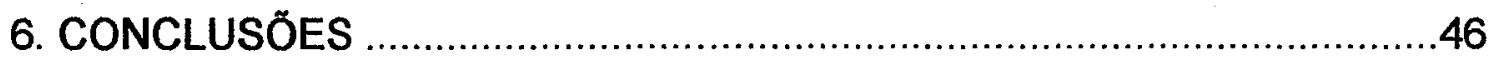

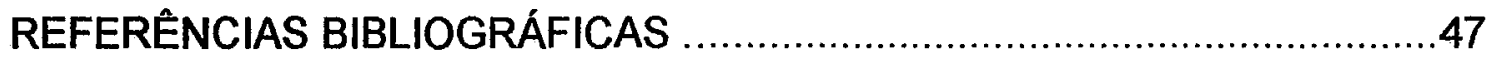




\section{LISTA DE FIGURAS}

Página

1 Fluxograma da metodologia para avaliação da distribuição de aflatoxinas nas frações de milho contaminado .28

2 Esquema da divisão da placa de cromatografia bidirecional e disposição das alíquotas do padrão e extrato da amostra 33 


\section{LISTA DE TABELAS}

Página

1 Níveis de tolerâncias para a classificação do milho em tipos, de acordo com a legislação brasileira

2 Concentração dos padrões empregados para detecção e quantificação das aflatoxinas

3 Propriedades físicas e classificação por tipo (Normas Brasileiras) das amostras de milho

4 Valores médios de aflatoxinas $B_{1}, B_{2}, G_{1}$ e $G_{2}$, em $\mu \mathrm{g} / \mathrm{kg}$, das duplicatas das frações estudadas, peso da fração e contribuição da fração para o nível de contaminação da amostra geral

5 Quadro de análise da variância

6 Médias do fator fração

7 Valores médios de aflatoxinas $B_{1}, B_{2}, G_{1}$ e $G_{2}$, em $\mu \mathrm{g} / \mathrm{kg}$, das duplicatas das frações estudadas, peso da fração e contribuição da fração para o nivel de contaminação da amostra geral

8 Quadro de análise da variância

9 Médias do fator tipo 45 


\title{
DISTRIBUIÇÃO DA CONTAMINAÇÃO COM AFLATOXINA NAS FRAÇÕES DE MILHO CONTAMINADOOBTIDAS APÓS SEPARAÇÃO GRANULOMÉTRICA E VISUAL
}

\author{
Autora: FABIANA SEGATTI PIEDADE \\ Orientador: PROF. DR. HOMERO FONSECA
}

\section{RESUMO}

Estudos têm mostrado que a contaminação com aflatoxinas está distribuida de forma extremamente heterogênea numa massa de grãos contaminada e que algumas frações específicas apresentam maior concentração.

No Brasil, apesar da importância econômica e da possibilidade já demonstrada da contaminação com aflatoxinas no milho, não existem estudos da distribuição desta toxina em frações granulométricas, obtidas nos processos de pré-limpeza utilizados no Brasil e também, nas frações visualmente separáveis e consideradas no processo de classificação do milho.

Assim, este trabalho teve como objetivo estudar a distribuição da contaminação, com aflatoxinas, em frações de milho, obtidas após peneiragem e separação visual de 30 amostras contaminadas.

O procedimento de preparo das amostras para análise de aflatoxinas consistiu-se em passar cada amostra na peneira de crivos circulares de $4,5 \mathrm{~mm}$ de diâmetro obtendo-se uma fração $\geq 4,5 \mathrm{~mm}$ e outra $<4,5 \mathrm{~mm}$. A fração $<4,5 \mathrm{~mm}$ foi moída e analisada. A fração $\geq 4,5 \mathrm{~mm}$ foi subdividida em duas: uma subamostra foi analisada e a outra passada por peneira de crivos 
circulares de 5,0 mm de diâmetro, sendo em seguida separada em grãos sadios (correspondendo a grãos regulares) e grãos não sadios (correspondendo a grãos ardidos, avariados, brotados, carunchados, chochos e quebrados), conforme a classificação oficial brasileira.

Os resultados mostraram que embora a concentração com aflatoxinas nas frações granulométricas tenha sido estaticamente maior em média para a fração $<4,5 \mathrm{~mm}$, a fração $\geq 4,5 \mathrm{~mm}$ apresentou para amostras especificas niveis de concentração mais elevados. Entretanto, se for considerado o peso e a concentração com aflatoxinas de cada fração, a contribuição da fração $\geq 4,5 \mathrm{~mm}$ para a concentração estimada nas amostras seria sempre maior em comparação a fração $<4,5 \mathrm{~mm}$.

Foram encontrados índices de correlação entre as percentagens dos grupos de defeitos definidos pela Classificação Oficial: a) grãos ardidos, queimados e brotados e b) grãos avariados, significativos com relação aos niveis de contaminação estimados para as frações granulométricas. Entretanto, outros estudos em nosso laboratório, ainda não publicados, não mostraram correlação significativa entre estes parâmetros. Portanto o uso dos índices de classificação para estimativa do nivel de contaminação com aflatoxinas deve ser melhor estudado.

A distribuição da contaminação observada nas frações separadas visualmente mostrou que a contaminação dos grãos não sadios foi estatisticamente maior que dos grãos sadios e em nenhuma amostra os grãos sadios apresentaram maior contaminação que os grãos não sadios.

Os niveis de contaminação dos grãos sadios foram menores de 20 $\mu \mathrm{g} / \mathrm{kg}$, máximo nivel permitido pela Legislação no Brasil (Brasil, 1996) em 87\% das amostras. Todas as frações de grãos sadios apresentaram contaminação maior que este nível. Considerando o peso e a concentração com aflatoxinas de cada fração, a contribuição dos grãos sadios para a concentração estimada 
seria sempre maior e a retirada dos grãos não sadios contribuiria para reduzir os niveis de contaminação das amostras.

Foram encontrados indices de correlação entre as percentagens dos grupos de defeitos definidos pela Classificação Oficial: a) grãos ardidos, queimados e brotados e b) grãos avariados, significativos com relação aos niveis de contaminação estimados para as frações de grãos sadios e não sadios. Entretanto, outros estudos em nosso laboratório, ainda não publicados, não mostraram correlação significativa entre estes parâmetros. Portanto o uso dos índices de classificação para estimativa do nível de contaminação com aflatoxinas deve ser melhor estudado. 


\title{
DISTRIBUTION OF AFLATOXIN CONTAMINATION IN FRACTIONS OF CONTAMINATED CORN OBTAINED AFTER GRANULOMETRIC AND VISUAL SEPARATION
}

\author{
Author: FABIANA SEGATTI PIEDADE \\ Adviser: PROF. DR. HOMERO FONSECA
}

\section{SUMMARY}

The aflatoxin contamination is extremally heterogenous in a lot of contaminated corn, but some fractions have shown to be more contaminated than others.

There is no data about the distribution of aflatoxins in fractions obtained after granulometric and visual separations, in Brasil, although corn have been a very important crop in the country.

This research had the objective to study the distribution of aflatoxin contamination in portions of corn, obtained after shaken on a grain-grading and visual separation of 30 contaminated samples.

The proceeding to prepare the samples for analyses was to pass each sample through a $4,5 \mathrm{~mm}$ round-hole sieve. It was obtained two fractions: one that was $\geq 4,5 \mathrm{~mm}$ and other $<4,5 \mathrm{~mm}$ and then the $<4,5 \mathrm{~mm}$ portion was analysed. The $\geq 4,5 \mathrm{~mm}$ portion was subdivided in two: one subsample was analysed and the other was passed through a $5,0 \mathrm{~mm}$ round-hole sieve, and than separated in sound kernels (regular kernels) and non sound kernels (fermented, injured, germinated, insect damaged, immature and broken, as defined by Brazilian Official Classification).

The results shown that although the concentration with aflatoxins in granulometric fractions have been statistically higher for $<4,5 \mathrm{~mm}$ fraction, the 
fraction $\geq 4,5 \mathrm{~mm}$ shown, for some specific samples, concentration levels higher. However, if it was considered the fraction, the contribution of $\geq 4,5 \mathrm{~mm}$ fraction for the concentration estimated for the samples it would be higher than $<4,5 \mathrm{~mm}$ fraction. The distribution of contamination observed in fractions segregated visually shown that the contamination of non sound kernels was statistically higher than sound kernels and the sound kernels never shown contamination levels higher than the sound kernels.

It was found correlation indexes with the percentages of the groups of defects, defined by Brazilian Oficial Classification: a) fermented, heated and sprouted grains and $b$ ) injured grains, statistically significants with the estimated contamination levels for the granulometric fractions. However, other studies in our laboratory, not published yet, showed not significant correlation to these percentages. Then the use of these indexes to estimate aflatoxin level of samples must be better studied.

The contamination levels of sound kernels were lower than 20 $\mu \mathrm{g} / \mathrm{kg}$, maximum level allowed in Brazil (Brasil, 1996), in $87 \%$ of the samples. The non sound Kernels showed contamination levels higher than this level in all of the samples.

Considering the weight and concentration of aflatoxins in each fraction, the contribution of sound kernels to the estimated concentration would be higher and the withdrawal of non sound kernels would contribute to reduce the level of contamination of the samples.

The correlation between types defined for the Official Classification and the contamination levels shown that these indexes were very low and no correlation was established among these parameters and the granulometric and visual fractions.

It was found correlation indexes with the percentages of the groups of defects, defined by Brazilian Oficial Classification: a) fermented, heated and 
sprouted grains and b) injured grains, statistically significants with the estimated contamination levels for the sound and non sound fractions. However, other studies in our laboratory, not published yet, showed not significant correlation to these percentages. Then the use of these indexes to estimate aflatoxin level of samples must be better studied. 


\section{INTRODUÇÃO}

O milho é, juntamente com o trigo e o arroz, um dos cereais mais importantes do mundo. Constitui um dos ingredientes básicos na alimentação humana, sendo utilizado como matéria prima nas indústrias de alimentos, para obtenção de amido, óleo, farinhas e fubá, entre outros produtos. Seu uso, na forma de silagem ou forragem para animais e como ingrediente em rações para alimentação animal, também é de grande importância, visto que, em países desenvolvidos, mais de $60 \%$ da produção de milho é utilizada como componente de rações para aves, porcos e animais ruminantes (FAO, 1993a).

O milho, devido à sua composição nutricional, é um substrato propício ao desenvolvimento de fungos, que podem causar diversos danos, tais como perdas nutricionais, consumo de matéria seca e produção de substâncias tóxicas, conhecidas por micotoxinas, que podem provocar danos à saúde do homem e/ou do animal.

A Organização das Nações Unidas para Alimentação e Agricultura (FAO) estima que, por ano, $25 \%$ da produção mundial de grãos é contaminada por micotoxinas (FAO, 1993b).

As principais micotoxinas relatadas no milho são as aflatoxinas, a ocratoxina $A$ e as toxinas de Fusarium: zearalenona, deoxinivalenol, toxina T-2 (Fonseca, 1997) e, mais recentemente, as fumonisinas (Meinders \& Hurburg, 1993). 
A contaminação de produtos agrícolas, com micotoxinas, ocorre de maneira bastante heterogênea, ou seja, poucos grãos altamente contaminados se distribuem entre muitos grãos não contaminados. Isso contribui para que ocorram grandes variações na concentração de micotoxinas, em amostras de um mesmo lote, tornando difícil a determinação da real concentração dessas micotoxinas. Dessa forma, a amostragem torna-se um procedimento extremamente crítico e importante (Scott, 1992).

As aflatoxinas foram as micotoxinas mais estudadas até hoje. Elas ocorrem em praticamente todo o mundo e apresentam vários efeitos deletérios, entre eles, ação mutagênica, teratogênica e carcinogênica (Bradburn \& Coker, 1993).

Estudos têm mostrado que grãos de milho, com alterações de cor, danos causados por insetos, desenvolvimento visivel de fungos e quebrados, apresentam maior probabilidade de estarem contaminados com aflatoxinas, assim como, as frações de material estranho e impurezas (Brekke et al., 1975; Johnson et al, 1969; Shotwell et al., 1972, 1974).

A determinação, das frações e tipos de grãos de milho, onde há maior contaminação com aflatoxinas, é de grande interesse, pois a remoção desse material contribuiria para uma redução na contaminação do lote.

Dado o volume e valor econômico do milho no Brasil, a melhoria de sua qualidade é muito importante para diminuir os riscos à saúde humana e animal e, também, as perdas econômicas decorrentes das doenças e mortes de animais causadas pela presença de aflatoxinas.

Não existem estudos da distribuição da contaminação com aflatoxinas em frações granulométricas, obtidas nos processos de pré-limpeza utilizados no Brasil, e também, nas frações visualmente separáveis e consideradas no processo de classificação do milho. 
Desta forma, este trabalho teve como objetivo, estudar a distribuição da contaminação com aflatoxinas em frações de milho obtidas após peneiragem e separação visual de lotes contaminados. 


\section{OBJETIVOS}

1. Verificar a distribuição das aflatoxinas nas frações granulométricas obtidas após peneiragem de um lote de milho em peneira de crivos circulares de $4,5 \mathrm{~mm}$ de diâmetro.

2. Verificar a distribuição das aflatoxinas em grãos sadios e não sadios, obtidos após separação visual de amostras contaminadas.

3. Verificar a correlação entre a classificação das amostras, em tipos definidos pela classificação brasileira, e os níveis de contaminação com aflatoxinas encontrados. 


\section{REVISÃO DE LITERATURA}

\subsection{Aflatoxinas}

\subsubsection{Importância e efeitos tóxicos}

A descoberta das aflatoxinas ocorreu no início da década de 60 , após a morte de 100.000 peruzinhos que haviam ingerido ração contendo farelo de amendoim, contaminado com A. flavus (Stevens et al. 1960, Asplin \& Carnaghan, 1961; Goldblatt, 1969).

As aflatoxinas são um grupo de substâncias produzidas pelo metabolismo secundário dos fungos Aspergillus flavus Link ex Fries, $A$. parasiticus Speare (Krogh, 1987) e A. nomius (Frisvad \& Thrane, 1996). São as micotoxinas mais conhecidas e compreendem hoje mais de 17 compostos, sendo as principais $B_{1}, B_{2}, G_{1}, G_{2}$, e $M_{1}$ (Abramson, 1991).

Sua representação, pelas letras B ("blue") e G ("green"), deve-se ao fato de apresentarem fluorescência azul-violeta ou esverdeada. Os índices 1 e 2 referem-se à sua mobilidade em cromatografia de camada delgada (Hartley et al., 1963, World Health Organization, 1979). Animais alimentados com ração contendo as aflatoxinas $B_{1}$ e $B_{2}$ excretam pelo leite, , metabólitos denominados de aflatoxinas $M_{1} \in M_{2}$, respectivamente (Allcroft \& Carnaghan, 1962; Allcroft et al, 1966).

As aflatoxinas são moléculas heterocíclicas, com átomos de oxigênio e anéis de bisfurano, que diferem entre si por pequenas variações em sua composição e estrutura molecular. Elas causam efeitos bioquímicos e 
biológicos na saúde de organismos vivos. Bioquimicamente, podem afetar o metabolismo de energia, o metabolismo de carboidratos e de lipídeos e o metabolismo dos ácidos nucléicos e das proteínas.

Parece haver diferenças de toxicidade entre as várias formas da aflatoxina, sendo $B_{1}>G_{1}>B_{2}>G_{2}$ (Carnaghan et al, 1963; Concon,1988). Destas, a aflatoxina $B_{1}$ é a mais tóxica e cancerígena, além de ser a mais comumente encontrada (Fonseca, 1968; Marasas \& Nelson, 1987).

Os efeitos biológicos das aflatoxinas são influenciados por: idade, sexo, espécie, condição nutricional (Hsieh et al., 1977), via de administração e a capacidade do animal de transformar biologicamente a toxina (Almeida, 1994). O nível da dose e o período de exposição do organismo à toxina são muito importantes. Diferentes espécies respondem diferentemente para os efeitos da aflatoxina (Moss \& Smith, 1985).

O conjunto de efeitos resultantes da ingestão de uma ou mais doses de alguma micotoxina é denominado de micotoxicose. Estas podem ser classificadas em agudas ou crônicas, de acordo com a quantidade de toxina ingerida ou sensibilidade do animal (Smith \& Moss, 1985).

A aflatoxicose aguda ocorre quando há ingestão de alimento altamente contaminado e provoca danos irreversíveis que podem levar à morte. Casos de aflatoxicose aguda ocorreram na Índia, onde 74 pessoas morreram e no Quênia, com 12 óbitos (Park \& Stolof, 1989).

$\mathrm{Na}$ aflatoxicose crônica, alimentos com baixos níveis de aflatoxinas são ingeridos por um prolongado período de tempo e os danos são reversíveis (Hsieh, 1986). O efeito mais comum deste tipo de contaminação é a diminuição da resistência imunológica e o câncer de fígado (Shank, 1978; Hsiesh, 1986; Mycotoxins, 1989). Esse tipo de intoxicação também está relacionada com cirrose infantil hindu, síndrome de Reye e encefalopatia (Hsieh, 1989). 
O mecanismo pelo qual as aflatoxinas produzem toxidez aguda é devido a uma ligação da aflatoxina $B_{1}$ ao DNA, alterando o espectro de absorção de $363 \mathrm{~nm}$ para 366-368 nm (Butler, 1974).

Segundo Turmo et al. (1991), a toxidez aguda da aflatoxina $B_{1}$ é, provavelmente, devido à produção de 2,3-dihidrodiol no fígado. Este derivado é responsável pela inibição da síntese de proteínas, apresentando, portanto, atividade imunossupressiva. $A$ taxa na qual aflatoxina $B_{1}$ é metabolizada para 2,3-dihidrodiol, é que determina a variação de susceptibilidade no animal. A metabolização da aflatoxina $B_{1}$ dihidrodiol para um derivado 2-3 epóxido, que pode reagir covalentemente com DNA, RNA e proteínas, pode ser o responsável pelos efeitos carcinogênicos, teratogênicos e mutagênicos da aflatoxina $B_{1}$.

A exposição crônica a baixos niveis de aflatoxinas, ocorre mais comumente do que a exposição aguda. Muitas evidências mostram que a exposição crônica a aflatoxinas leva ao desenvolvimento de câncer mais rapidamente que a exposição aguda, representando, desse modo, um sério problema de saúde pública (Roebuck \& Maxuitenko, 1994).

As aflatoxinas podem causar dano ao fígado em animais domésticos e experimentais (Stark, 1986) e embora esse órgão seja o alvo primário, as lesões cancerígenas também foram observadas, em muitos casos, nos rins, cólon, pulmões e glândulas lacrimais de vários animais alimentados com rações contaminadas com aflatoxina (Stoloff, 1977).

A DL50 média ( $\mathrm{mg} / \mathrm{kg}$ de peso, via oral), de aflatoxina $B_{1}$ foi estabelecida para os seguintes animais: coelho, 0,3; pato, 0,3; gato, 0,6; porco, 0,6; truta, 0,8; cachorro, 1,0; porquinho da Índia, 1,4; carneiro, 2,0; macaco, 2,2; camundongo, 9,0; hamster, 10,2; pintinho, 11,5; rato (macho), 7,2 e rato (fêmea), 17,9 (Marasas \& Nelson, 1987).

Segundo Rodricks \& Stoloff (1977), as aflatoxinas exibem um efeito "carry-over", ou seja, podem ocorrer resíduos de aflatoxinas na carne, leite e ovos de animais consumindo rações contaminadas. 
Os principais produtos associados com contaminação de aflatoxinas são amendoim, milho, avelãs, nozes, sementes de algodão, arroz, frutas secas (FAO, 1993b) e castanha do Brasil (Fonseca, $\mathrm{H}^{{ }^{1}{ }^{1} \text { ) }}$

Muitos paises estabeleceram limites de contaminação com aflatoxinas para a comercialização de seus produtos. Esses limites variam de zero a $50 \mu \mathrm{g} / \mathrm{kg}$ (FAO, 1995). No Brasil, a presença de aflatoxinas nos alimentos é regulada pela resolução $n^{\circ} 34 / 76$, do CNNPA (Comissão Nacional de Normas e Padrões para Alimentos), do Ministério da Saúde, que estabelece, como limite máximo, $30 \mu \mathrm{g} / \mathrm{kg}$, para a somatória das aflatoxinas $B_{1}$ e $G_{1}$ (Brasil, 1977). $O$ Ministério da Agricultura adotou o limite de $20 \mu \mathrm{g} / \mathrm{kg}$, para a soma das aflatoxinas $B_{1}, B_{2}, G_{1}$ e $G_{2}$ (Brasil, 1996).

\subsubsection{Condições para produção}

A contaminação do milho com aflatoxinas pode ocorrer ainda no campo, na colheita ou durante a estocagem e processamento (Heathcote, 1978).

Aspergillus flavus e A. parasiticus, mesmo sendo considerados fungos que se desenvolvem principalmente no pós-colheita e no armazenamento, podem infectar a planta ainda nos primeiros estágios de seu desenvolvimento (Betina, 1989).

Segundo Diener et al. (1987), o A. parasiticus, parece estar mais adaptado ao solo, sendo predominante em vagens de amendoim, e $\circ$ A. flavus, por estar mais adaptado ao ambiente aéreo e foliar, é dominante em milho, caroço de algodão e nozes, embora seja comum no solo, especialmente em solo cultivado cujos resíduos são incorporados, e em todo tipo de vegetação em

\footnotetext{
${ }^{1}$ Fonseca, H. (Escola Superior de Agricultura "Luiz de Queiroz", Departamento de Agroindústria, Alimentos e Nutrição, Piracicaba), comunicação pessoal, 1999.
} 
decomposição, como grãos com alto teor de umidade (Christensen \& Kaufman, 1969).

Tanto A. flavus como A. parasiticus, podem infectar o milho no campo (Hesseltine et al., 1981), porém o A. flavus parece ser o dominante na produção de aflatoxina (Calvert et al., 1978).

Segundo Lillehoj \& Hesseltine (1977), os principais fatores que influenciam a contaminação do milho no campo são: (1) Estresse hídrico, ou de outro tipo, que predispõe a planta ao ataque de alguns insetos e fungos, incluindo os produtores de toxinas; (2) dano nas sementes, que é pré-requisito para estabelecimento da infecção por A. flavus; (3) Danos causados por insetos, favorecendo a infecção por $A$. flavus e (4) insetos vetores de inóculo inicial de fungo.

Convém lembrar que, a infecção do milho por $A$. flavus no campo, irá exercer profunda influência na armazenagem do mesmo (Lillehoj \& Hesseltine, 1977).

Após a colheita, segundo Goldblatt (1971), o parâmetro mais importante, com relação à presença da contaminação por aflatoxinas, é a umidade. $\mathrm{O}$ tempo decorrido entre a colheita e a secagem é um aspecto crítico na prevenção da formação de aflatoxinas (Hayes et al., 1966). Segundo Bradburn et al. (1993), mesmo milho inoculado, com alto teor de umidade, não se contaminará se for seco e armazenado sob condições favoráveis, em 48 horas.

Segundo Palmgren \& Hayes (1987), a produção de aflatoxinas, no milho recém-colhido, pode ser prevenida com sucesso através de boas práticas de colheita, secagem e armazenamento e reduzindo, especialmente, a incidência de danos físicos (Betina, 1989).

Os principais fatores que regulam o crescimento de fungos e produção de aflatoxinas são: umidade do substrato, umidade relativa e temperatura (Marasas \& Nelson, 1987). 
Segundo Win \& Lane (1978), o crescimento de A. flavus e produção de aflatoxina requer uma umidade relativa de equilíbrio (URE) mínima de $85 \%$, o que corresponde a um teor de umidade de $18-18,5 \%$ no milho. Um aumento da umidade relativa para $86-87 \%$ induzirá um rápido crescimento fúngico e produção de aflatoxina. Milho infectado sujeito a uma URE maior que $90 \%$ pode resultar em niveis significativos de aflatoxina em 48 horas.

Segundo Diener \& Davis (1966), a temperatura ótima para produção de aflatoxinas por $A$. flavus é de 24 a $25^{\circ} \mathrm{C}$. Nestas condições, esses autores observaram que, com 5 dias de incubação a produção de aflatoxinas já era elevada, tanto em grãos como em meio de cultura. A temperatura mínima limitante para crescimento do fungo está entre 10 e $13 \pm 1^{\circ} \mathrm{C}$ e máxima entre 40 e $41,5 \pm 1,5^{\circ} \mathrm{C}$ (Diener \& Davis, 1969; Schindler et al., 1967; Schroeder \& Hein, 1967).

Para A. parasiticus, a faixa ótima de temperatura para produção de aflatoxinas é de 25 a $30^{\circ}$. Nestas condições, a produção de aflatoxinas já é elevada com 3 dias de incubação, tanto em grãos como em meio de cultura (Dienner \& Davis, 1966).

Trucksess et al. (1988), verificaram que, nas temperaturas de $26^{\circ} \mathrm{C}$ e $32^{\circ} \mathrm{C}$, o limite mínimo de atividade de água para produção de aflatoxinas por A. flavus, no milho, foi de 0,85 , o que equivale a um teor de umidade de $16 \%$ (diferindo das observações de Win \& Lane, 1978). Para o crescimento do fungo, entretanto, o limite mínimo de atividade de água foi de $A w=0,73$. $\mathrm{Na}$ temperatura de $16^{\circ} \mathrm{C}$ não houve produção de aflatoxina mesmo com $A w=0,96$.

Segundo Ross et al. (1979), citado por Bradburn et al. (1993), o conteúdo máximo de umidade, para um armazenamento seguro do milho, é de $13 \%$ para 1 ano e $11 \%$ para 5 anos. 


\subsection{Ocorrência no milho}

Levantamentos da FAO (1993b) mostram significativa contaminação com aflatoxinas no milho e produtos do milho em regiőes tropicais como, América Latina e Caribe, sendo relativamente menor em regiões temperadas como Canadá, França, Reino Unido, Senegal e Japão.

Vários trabalhos têm mostrado a ocorrência de aflatoxinas no milho em diversas regiões do mundo.

Zuber et al (1986), realizaram uma coleta, nos anos de 1979 e 1981, de 281 amostras de milho provenientes de 3 e 10 países, respectivamente, localizados em regiões tropicais e subtropicais. Os dados mostraram que a incidência variou de 42 a $100 \%$ de contaminação nas amostras provenientes do México, Tailândia, Colômbia, Índia e Costa Rica (com níveis médios variando de 1 a $98 \mu \mathrm{g} / \mathrm{kg}$ ). A aflatoxina, não foi detectada em amostras de Burma, República da África do Sul, Costa do Marfim, Equador e Filipinas, ao passo que, Bolivia, Brasil e Guana apresentaram incidência e niveis muito baixos (traços).

Castor et al. (1987), analisaram 269 amostras coletadas no varejo, no Haiti, em janeiro, julho e outubro de 1983 e janeiro de 1984, e verificaram que $69 \%$ continham aflatoxina, das quais $22 \%$, mais de $20 \mu \mathrm{g} / \mathrm{kg}$ e $10 \%$ mais de $100 \mu \mathrm{g} / \mathrm{kg}$.

Özay \& Heperkan (1989), relataram sua ocorrência na Turquia, em $16 \%$ das 167 amostras analisadas, em níveis variando de 2 a $74 \mu \mathrm{g} / \mathrm{kg}$.

Na Argentina, Chulze et al. (1989), relataram a ocorrência em 5 $(3,3 \%)$ e $2(1,3 \%)$ amostras dentre 150 analisadas, contaminadas com aflatoxinas $B_{1}$ e $G_{1}$, respectivamente, com níveis variando de 10 a $50 \mu \mathrm{g} / \mathrm{kg}$.

Nos E.U.A., segundo Wood (1992), o mitho vem sendo monitorado desde 1965, quanto à presença de aflatoxinas, no entanto, nos anos de 1989 e 
1991, o milho de muitas áreas do pais apresentaram altos niveis de contaminação.

Em uma revisão, sobre a contaminação de aflatoxinas no milho, Bradburn et al. (1993), relataram que estas ocorrem em todo o mundo, desde a América do Norte e Sul até a África e Ásia e que os níveis atingem 12.500 $\mu \mathrm{g} / \mathrm{kg}$, mas a maioria dos niveis encontrados estavam abaixo de $1.000 \mu \mathrm{g} / \mathrm{kg}$.

Bryden et al. (1996), analisaram 70 amostras de milho australiano, das quais 10 apresentavam contaminação com aflatoxinas, com niveis variando de $0,6-13,3 \mu \mathrm{g} / \mathrm{kg}$, com média de $3 \mu \mathrm{g} / \mathrm{kg}$. Foram também analisadas 10 amostras das Filipinas, das quais 5 continham aflatoxinas com média de 36 $\mu \mathrm{g} / \mathrm{kg}$ (variando de 1-136 $\mu \mathrm{g} / \mathrm{kg}$ ), e 12 amostras do Vietnã, sendo que 11 apresentavam contaminação com média de $110 \mu \mathrm{g} / \mathrm{kg}$ (variando de 2-195 $\mu \mathrm{g} / \mathrm{kg}$ ).

Resnik et al. (1996), analisaram 2271 amostras de milho, coletadas entre os anos de 1983 e 1994 das províncias de Buenos Aires e Santa Fé, na Argentina, quanto à presença de aflatoxinas. Do total de amostras analisadas, $445(19,6 \%)$ estavam contaminadas com a $B_{1}$ (com níveis médios variando de 4,3 a $32,1 \mu \mathrm{g} / \mathrm{kg}$ ). A $B_{2}$ estava presente em 92 amostras $(4,1 \%)$, com niveis variando de 1,6 a $14,9 \mu \mathrm{g} / \mathrm{kg}$. Apenas uma amostra estava contaminada com a $G_{1}(8 \mu \mathrm{g} / \mathrm{kg})$ e a $G_{2}$ não foi detectada em nenhuma das amostras.

Sétamou et al. (1997), encontraram aflatoxinas $B_{1}$ e $B_{2}$, em $42,4 \%$ e 30\% de 80 e 60 amostras coletadas em 1994 e 1995 em Benim, na África. Os niveis das aflatoxinas $B_{1}+B_{2}$ nas amostras contaminadas variaram de 16,7 a $241 \mu \mathrm{g} / \mathrm{kg}$ em 1994 e 23,3 a 262,9 $\mu \mathrm{g} / \mathrm{kg}$ em 1995.

No Brasil, vários trabalhos vêm constatando a presença de aflatoxinas em milho e derivados. Fonseca et al. (1982) e Fonseca et al. (1983), estudaram a ocorrência de aflatoxinas no milho proveniente do varejo de várias 
cidades em 6 regiões do Estado de São Paulo e verificaram que apenas 6 $(4,7 \%)$ das 128 amostras analisadas estavam contaminadas em níveis que variavam de 41 a $2.000 \mu \mathrm{g} / \mathrm{kg}$.

Sabino et al. (1988), determinaram os níveis de aflatoxinas em 358 amostras de milho procedentes dos Estados de Santa Catarina, Minas Gerais, São Paulo, Paraná, Rio Grande do Sul e Espírito Santo, e detectaram aflatoxina $B_{1}$ em $12,3 \%$ destas amostras, em concentrações que variavam de 10 a 900 $\mu \mathrm{g} / \mathrm{kg}$.

Baldissera et al. (1994), realizaram 1.131 análises micotoxicológicas em alimentos, para consumo animal, oriundos da Região Sul do Brasil. Destas, $51,2 \%$ era milho, $30,85 \%$ ração balanceada e $17,95 \%$ outros substratos constituídos por arroz, sorgo, farelos de trigo e de amendoim provenientes da Região Sul do Brasil. Do total, 451 (89,84\%) amostras de milho estavam contaminadas com aflatoxina, sendo o nível máximo de contaminação de $1.087 \mu \mathrm{g} / \mathrm{kg}$.

Sylos et al. (1996), verificando a incidência de aflatoxina no milho brasileiro, encontraram que 28 das 48 amostras de milho do Sul do Brasil (Estados de Rio Grande do Sul, Santa Catarina e Paraná), apresentaram aflatoxina $B_{1}$ na faixa de traços até $2.151 \mu \mathrm{g} / \mathrm{kg}$. As 32 amostras de milho provenientes do Estado de São Paulo não estavam contaminadas.

Mennegazzo \& Lazzari (1996), avaliaram o nivel de aflatoxina presente nos grãos de milho utilizado em rações de aves e suínos nos três Estados da região sul do Brasil, no período de janeiro de 1992 a dezembro de 1995. Os niveis médios encontrados foram $5,3,0,6,13,8$ e $23,8 \mu \mathrm{g} / \mathrm{kg}$ para os anos de 1992 a 1995, respectivamente.

Santúrio et al. (1997), analisaram 5.335 amostras de alimentos, provenientes do Sul do Brasil, no período de março de 1986 a março de 1997. O principal produto analisado foi o milho (2.460 amostras), com $1.273(51,8 \%)$ positivas para aflatoxina com um nível médio de $36,2 \mu \mathrm{g} / \mathrm{kg}$ e $14,2 \mathrm{mg} / \mathrm{kg}$ de 
nivel máximo. Foram também analisadas 36 amostras de milho tipo pipoca e $33,3 \%$ estavam contaminadas, apresentando uma média de contaminação de $11,5 \mu \mathrm{g} / \mathrm{kg}$ com nível máximo de $131,4 \mu \mathrm{g} / \mathrm{kg}$.

Glória et al. (1997), analisaram 292 amostras de grãos destinados à indústria alimentícia do Estado de São Paulo. Noventa e oito $(33,7 \%)$ amostras estavam contaminadas, em niveis que variavam de 11 a $107 \mu \mathrm{g} / \mathrm{kg}$, somadas as aflatoxinas $B_{1} e G_{1}$.

\subsection{Distribuição da aflatoxina nas frações de milho}

Embora a contaminação com aflatoxinas em grãos de milho não esteja distribuída de forma homogênea, alguns estudos mostraram que grãos quebrados, com alterações de cor, danificados por insetos, mofados, bem como as frações de impureza e material estranho, podem estar mais contaminados com aflatoxinas.

\subsubsection{Separação Granulométrica de Impurezas e material estranho}

Pela legislação americana, impurezas e material estranho é considerado todo material que passar através de uma peneira de crivos circulares de 12/64 polegadas ou 4,8 mm de diâmetro, mais todo o material que não constitui grão e que fica retido na peneira (Meinders \& Hurburg, 1993). No Brasil, utiliza-se uma peneira de crivos redondos de $5 \mathrm{~mm}$ (Brasil, 1976).

A retirada de materiais estranhos e impurezas de um lote de milho contribui para minimizar a contaminação fúngica durante a estocagem e o processamento (Goldblatt, 1971).

Segundo Puzzi (1986), o produto contendo impurezas e matérias estranhas, é portador de maior quantidade de microrganismos responsáveis 
pelo aumento do processo respiratório em grãos armazenados (Christensen \& Kaufman, 1969).

Milner \& Geddes (1954), mostraram que o rápido aumento do processo respiratório, em cereais que apresentavam mais de $14 \%$ de umidade, era acompanhado de aumento de colônias de fungos.

Seitz et al. (1982), observaram que o desenvolvimento fúngico teve início muito cedo na fração de impurezas de amostras de milho e que a taxa de respiração foi mais rápida e mais intensa que nas amostras de grãos inteiros.

Sauer et al. (1992), estudando a influência de fungos no armazenamento verificou que, somente $10 \%$ do processo respiratório no milho com $15-16 \%$ de umidade, foi devido aos grãos, sendo o restante proveniente de fungos.

O aumento do processo respiratório, pode levar ao aquecimento dos grãos, formando o que se denomina de "bolsa de calor". A formação da bolsa de calor leva a um rápido aumento da temperatura da zona aquecida, contribuindo para uma rápida deterioração do produto, favorecendo, portanto, a produção de micotoxinas (Christensen \& Kaufmann, 1969; Puzzi, 1986).

Johnson et al. (1969), estudaram as frações de impurezas e material estranho de 21 amostras de milho, quanto à presença de micotoxinas, $e$ verificaram que a aflatoxina estava presente nessas frações de todas as amostras analisadas. $O$ material restante, após a retirada das impurezas $e$ material estranho, foi analisado e apenas uma amostra apresentou contaminação em baixos níveis.

A operação de pré-limpeza do milho, praticada nas indústrias, tem o objetivo de eliminar grande parte das impurezas e material estranho de um lote. Após essa operação, o material rejeitado, pode ser vendido por um preço mais barato que o milho. Segundo Meinders \& Hurburg (1993), as micotoxinas 
mais comumente encontradas em rejeito de milho são as aflatoxinas, e mais recentemente, as fumonisinas.

Brekke et al. (1975), testaram a pré-limpeza como método de redução de aflatoxinas em 10 lotes de milho contaminado. Os resultados mostraram que em apenas um lote houve redução do conteúdo inicial de aflatoxinas (de 70 para $15 \mu \mathrm{g} / \mathrm{kg}$ ), indicando que a sua maior parte estava presente no rejeito. Os maiores níveis de contaminação foram encontrados em dois lotes que apresentaram os maiores niveis de grãos danificados após a prélimpeza (3 e 5\%).

\subsubsection{Separação visual de grãos quebrados, danificados, com}

\section{alterações na coloração e aparentemente sadios}

Após a remoção das impurezas e de material estranho de um lote de milho, ainda permanecem grãos danificados e quebrados, que são mais sujeitos à ação de fungos do que grãos inteiros (Christensen \& Kaufmann, 1969)

Rambo et al. (1974), reportaram que a incidência de $A$. flavus em amostras de milho coletadas em 1971 e 1972, no Estado de Indiana, E.U.A, foi maior em grãos fisicamente danificados.

Seitz et al. (1982), observaram que a quantidade de danos e incidência de $A$. flavus influenciou positivamente a taxa de respiração de um lote de milho armazenado com alto grau de umidade a $29,4^{\circ} \mathrm{C}$. As taxas de respiração nos grãos danificados e inoculados, foram mais altas e mais intensas que nos grãos não danificados $e$ inoculados. Grãos não danificados $e$ inoculados apresentaram um discreto aumento na taxa de respiração durante a estocagem. Ao final da estocagem, o conteúdo de aflatoxinas, nas amostras inoculadas, foi bem maior que nos controles. 
Stroshine \& Yang (1990), verificaram que a velocidade de deterioração do milho úmido foi 2 a 3 vezes maior em lotes contendo $45 \%$ de grãos danificados do que em lotes com $15 \%$ de danos.

Segundo Qasem \& Christensen (1960), Steele et al. (1969) e Tuite et al. (1985), danos no germe ou embrião, são os que apresentam maior influência no desenvolvimento fúngico.

Seitz et al (1982), relataram que os fungos invadem grãos com germes danificados mais rápido do que grãos com outros tipos de danos, no entanto essa diferença tende a diminuir ao longo do armazenamento.

A ação de microrganismos sobre grãos armazenados, também afeta a coloração natural dos grãos, principalmente no germe ou embrião, local preferido para a sua invasão (Sauer, 1992).

Qasem \& Christensen, (1958, 1960), verificaram germes com coloração marrom escuro em grãos de milho inoculados e armazenados. Nas amostras livres de fungos, não houve modificação na cor.

Shotwell et al. (1972), estudaram a distribuição da aflatoxina em 34 amostras de milho contaminadas e não contaminadas. As frações estudadas foram: grandes pedaços de milho, grãos danificados (quebrados e embolorados), grãos inteiros não danificados $e$ as impurezas e material estranho. Os resultados mostraram que a aflatoxina, não estava concentrada apenas nas impurezas e no material estranho de um lote de milho. Outras frações como, grãos danificados e grandes pedaços de milho, que não passavam pela peneira de $12 / 64$ polegadas ou $4,8 \mathrm{~mm}$, estavam altamente contaminadas e que a retirada apenas das impurezas e do material estranho, que passavam pela peneira, não era suficiente para eliminar a aflatoxina. Os 
autores verificaram, entretanto, que grãos inteiros não danificados não apresentaram contaminação com aflatoxinas.

Shotwell et al. (1974), estudaram a distribuição das aflatoxinas em 10 amostras de milho contaminado. As fraçōes estudadas foram: impurezas e material estranho; grãos danificados, quebrados e com alterações na coloração; e grãos aparentemente sadios. A análise de cada fração, indicou que as aflatoxinas não estavam presentes apenas nas frações como impurezas, material estranho e grãos danificados, mas também em grãos com alteração na coloração e grãos aparentemente sadios. A remoção das frações estudadas, de cada lote, contribuiu para uma redução da contaminação, a níveis menores que $10 \mu \mathrm{g} / \mathrm{kg}$ em apenas 2 amostras, enquanto que nas demais, os niveis permaneceram maiores que $20 \mu \mathrm{g} / \mathrm{kg}$.

Lillehoj \& Fennel (1975), estudaram a incidência de A flavus em 6 amostras de milho retiradas de locais com grãos cuja coloração estava alterada na superfície do lote. A percentagem de incidência de A. flavus, nas 6 amostras, variou de 23 a $80 \%$, comparado a $10 \%$ de incidência em amostras de milho que não apresentavam alteração na coloração. A amostra com $80 \%$ de $A$. flavus, continha 400 ppb de aflatoxina, que não foi detectada nas outras 5 amostras.

Brekke et al. (1975), analisaram a fração de grãos inteiros, aparentemente saudáveis, de 10 lotes de milho contaminados com aflatoxina. Os resultados mostraram que, embora essa fração constituísse a maior parte de cada amostra, ainda continha 60 a $140 \mu \mathrm{g} / \mathrm{kg}$ de aflatoxina $B_{1}$, representando 50 a $10 \%$ da contaminação inicial.

Fennel (1975) relataram que a incidência de A. flavus em grãos de espigas danificadas por insetos foi significantemente maior $(6,3 \%)$ do que em espigas não danificadas (2,5\%). 
A distribuição de aflatoxina em amostras de milho apresentando danos por insetos, no Estado da Carolina do Sul, foi relatada por Shotwell et al. (1975). As frações de grãos que apresentavam danos causados por insetos, representavam 2 a $29 \%$ do peso da amostra e 61 a $69 \%$ do total de aflatoxina. As frações contendo grãos aparentemente sadios tinham $67-87 \%$ do peso total da amostra, sendo que 4 delas não apresentavam contaminação com aflatoxinas e 2 tinham 9 e 13\% do total de aflatoxina da amostra. A fração apresentando grãos com alteração na cor, danificados e quebrados correspondia a 3 a $39 \%$ do peso e 3 a $39 \%$ de aflatoxina.

Hesseltine et al. (1976), estudaram a ocorrência de aflatoxinas na colheita do milho da safra de 1973, em 7 localidades na Carolina do Sul. Conforme a percentagem de dano por insetos aumentava, a quantidade de aflatoxina no milho também aumentava. $O$ aumento dos danos causados por insetos também coincidiu com maiores niveis de contaminação do milho por $A$. flavus.

A distribuição da contaminação com aflatoxina em espigas de milho, que apresentavam danos causados por insetos e esporos visiveis de $A$. flavus, foi relatada por Lee et al. (1980). Segundo esses autores, 0 desenvolvimento fúngico parecia estar nos grãos que apresentavam danos causados por insetos, ou próximos a eles. Havia uma grande variação no conteúdo de aflatoxina entre os grãos.

Echandi (1986), investigou a infecção de $A$ flavus e formação de aflatoxinas no grão de milho danificado e não danificado. A contaminação com aflatoxinas foi muito maior nos grãos danificados e inoculados do que nos grãos não danificados e inoculados. Em estudos subsequentes, fazendo inoculação de espigas, os resultados foram semelhantes, porém com niveis de contaminação muito menor. $O$ autor concluiu que grãos de milho na espiga são mais resistentes à contaminação com aflatoxinas 
Mc Millian (1986), em levantamentos realizados na Georgia, durante os anos de 1977 a 1984, verificou que a média de contaminação com aflatoxinas aumentou conforme o aumento da percentagem de espigas danificadas por insetos.

Castor et al. (1987), constataram contaminação com aflatoxinas em $69 \%$ de 269 amostras coletadas no Haiti entre 1983 e 1984 . A incidência e concentração de aflatoxinas, aumentaram concomitantemente com a incidência de A. flavus.

Sétamou et al. (1997) encontraram A. flavus em $80 \%$ e $60 \%$ de 80 e 60 campos amostrados em 1994 e 1995, em Benin, na África. 42,4\% das amostras estavam contaminadas em 1994 e 30\% em 1995. Os níveis das aflatoxinas $B_{1}+B_{2}$, nas amostras contaminadas, variaram de 16,7 a $241 \mu \mathrm{g} / \mathrm{kg}$ em 1994 e de 23,3 a 262,9 $\mu \mathrm{g} / \mathrm{kg}$ em 1995. 


\section{MATERIAL E MÉTODOS}

\subsection{Material}

O material constituiu-se de amostras contaminadas com aflatoxinas, que foram retiradas de cargas de milho ao chegarem a uma indústria de Mogi Guaçu, S.P.

\subsection{Métodos}

\subsubsection{Amostragem}

Foram realizadas duas amostragens em diferentes períodos (novembro e janeiro), nas quais foram retiradas 16 e 14 amostras respectivamente.

De 6 a 9 subamostras, dependendo do tamanho da carga a ser amostrada, foram retiradas através de um amostrador mecânico de diferentes pontos. As subamostras foram então reunidas, para formar uma amostra de aproximadamente $3 \mathrm{~kg}$, considerada representativa de cada carga de milho.

As amostras obtidas foram checadas para presença de aflatoxinas, conforme protocolo utilizado pela indústria, pelo teste de triagem da luz ultravioleta. Este constituiu-se em observar cada amostra em uma cabine de visualização equipada com luz ultravioleta para detecção de pontos com a fluorescência BGY (Bright greenish yellow). As amostras que apresentaram um número de pontos fluorescentes maior ou igual a doze foram consideradas 
provavelmente contaminadas e posteriormente foram checadas para confirmação da contaminação com aflatoxinas por um método de imunoenssaio da marca Vicam.

As amostras comprovadamente contaminadas foram identificadas e transportadas para o Laboratório de Micotoxinas da ESALQ-USP, onde foram armazenadas em congelador à temperatura de $-18^{\circ} \mathrm{C}$, para evitar atividade de microrganismos e insetos antes da utilização.

\subsubsection{Classificação das amostras}

As amostras foram inspecionadas e classificadas pelo setor de recepção de matéria-prima da indústria, de acordo com a Portaria $n^{\circ} 845$, de 8 de novembro de 1976, do Ministério da Agricultura, em milho tipos 1, 2, 3 ou AP (abaixo do padrão), conforme apresentado na Tabela 1.

Para classificação das amostras, essas foram homogeneizadas e $250 \mathrm{~g}$ de material foram retirados manualmente.

Cada amostra foi submetida, então, à peneira de $5 \mathrm{~mm}$ de diâmetro para retirada do material a ser considerado como parte da fração definida como impurezas, material estranho e fragmentos.

A inspeção visual das amostras de classificação, já peneiradas, permitiu a identificação, separação e mensuração, através da pesagem, dos defeitos definidos de acordo com a classificação oficial.

De acordo com o artigo 13, da Portaria $n^{\circ} 845$ de 1976 (Brasil, 1976) e anexo da Portaria $n^{\circ} 11$ de 1996 (Brasil, 1997) os termos usados nas especificações são definidos do seguinte modo:

GRÃOS ARDIDOS - grãos ou pedaços de grãos que perderam a coloração ou cor características, por ação do calor e umidade ou fermentação em mais de 1/4 (um quarto) do tamanho do grão. 
GRÃOS AVARIADOS - grãos ou pedaços de grãos, grãos chochos, imaturos, os atacados por insetos, animais roedores ou parasitas, os fermentados até $1 / 4$ (um quarto) do tamanho do grão, bem como os prejudicados por diferentes causas.

GRÃOS BROTADOS - grãos ou pedaços de grãos que apresentaram germinação visível.

GRÃOS CARUNCHADOS - grãos ou pedaços de grãos furados ou infestados por insetos vivos ou mortos.

GRÃOS CHOCHOS - grãos enrugados por deficiência de desenvolvimento.

GRÃOS QUEBRADOS - pedaços de grãos sadios, que ficaram retidos na peneira de crivos circulares de $5 \mathrm{~mm}$ de diâmetro (12/64 polegadas).

GRÃOS REGULARES - grãos normalmente desenvolvidos, que apresentavam boas condições de maturidade e conservação

IMPUREZAS - são consideradas as do próprio produto, bem como os grãos ou fragmentos de grãos que vazarem numa peneira de crivos circulares de $5 \mathrm{~mm}$ de diâmetro (12/64 polegadas).

MATÉRIAS ESTRANHAS - são consideradas os grãos ou sementes de outras espécies, bem como os detritos vegetais, sujidades e corpos estranhos de qualquer natureza, não oriundos do produto.

A portaria 11/96 (Brasil,1997) definiu que juntamente com os grãos ardidos e brotados deve-se juntar os grãos queimados e mofados para efeito de tipificação, que estão definidos a seguir;

GRÃOS QUEIMADOS: grãos que apresentam alteração na coloração normal por ação de altas temperaturas dos GRÃOS MOFADOS.

GRÃOS MOFADOS: grãos inteiros ou quebrados que apresentarem no todo ou em parte, fungo (bolor), visível a olho nu. 
Os grãos quebrados, carunchados e chochos foram considerados como pertencentes à classe dos avariados, assim como os ardidos e brotados, porém foram computados separadamente.

Cada um desses grupos de defeitos foi mensurado através da sua percentagem, em peso, relativa aos $250 \mathrm{~g}$ da amostra utilizada para sua separação.

Tabela 1. Niveis de tolerâncias para a classificação do milho em tipos, de acordo com a legislação brasileira (Brasil, 1976).

\section{TOLERÂNCIAS}

\begin{tabular}{|c|c|c|c|c|}
\hline \multirow{2}{*}{ TIPO } & \multirow{2}{*}{ Umidade } & \multirow{2}{*}{$\begin{array}{l}\text { Matérias Estranhas, } \\
\text { Impurezas e } \\
\text { Fragmentos }\end{array}$} & \multicolumn{2}{|c|}{ Avariados } \\
\hline & & & Total & $\begin{array}{c}\text { Máximo de } \\
\text { Ardidos e } \\
\text { Brotados } \\
\end{array}$ \\
\hline 1 & $14,5 \%$ & $1,5 \%$ & $11 \%$ & $3 \%$ \\
\hline 2 & $14,5 \%$ & $2,0 \%$ & $18 \%$ & $6 \%$ \\
\hline 3 & $14,5 \%$ & $3,0 \%$ & $27 \%$ & - \\
\hline A.P.* & $14,5 \%$ & \multicolumn{3}{|c|}{ (a serem especificados em cada caso) } \\
\hline
\end{tabular}

\subsection{Determinação do teor de umidade}

A determinação do teor de umidade das amostras de milho, foi determinada através do equipamento Motomco, modelo $909 \mathrm{E}$, durante sua classificação.

No laboratório, apenas como informação adicional para fins de armazenamento, foi determinado o teor de umidade das amostras de milho de 
acordo com a metodologia da American Association of Cereal Chemists (AACC, 1995), em estufa $a 103^{\circ} \mathrm{C}$, conforme segue abaixo:

Para cada amostra foram pesadas, em placas de Petri taradas, aproximadamente $15 \mathrm{~g}$ do material (não moído). Zerando-se a balança, as placas foram tampadas, juntamente com o conteúdo, e pesadas novamente, obtendo-se P1. A seguir, foram colocadas parcialmente tampadas na estufa a $103 \pm 1{ }^{\circ} \mathrm{C}$ por 72 horas. Após esse período, foram tampadas e levadas para um dessecador até atingirem a temperatura ambiente, sendo pesadas em seguida (P2).

A perda de peso encontrada, correspondeu à percentagem de umidade, ou seja:

$$
\% \text { umidade }=\frac{(\mathrm{P} 1-\mathrm{P} 2)}{\text { Peso original da amostra }} \times 100
$$

\subsection{Avaliação da distribuição das aflatoxinas nas} frações granulométricas obtidas após peneiragem.

Com o objetivo de obter-se o material para estudo, as amostras foram preparadas como mostrado no fluxograma da Figura 1

Cada amostra, previamente classificada, de aproximadamente 3 $\mathrm{kg}$, foi passada em uma peneira de crivos redondos de $4,5 \mathrm{~mm}$ de diâmetro (conforme levantamento feito, este é o crivo mais utilizado pelas indústrias na pré-limpeza) levando, portanto, à obtenção de duas frações: uma fração que ficou retida na peneira de $4,5 \mathrm{~mm}$ (partículas maiores ou iguais a $4,5 \mathrm{~mm}$ ), e outra que passou pela peneira de 4,5 mm (partículas menores que 4,5 mm).

A fração, de cada amostra, retida na peneira de $4,5 \mathrm{~mm}$ foi em seguida, subdividida em homogeneizador/subamostrador, tipo Gamet, em duas subamostras, A e B. 
Para avaliação da distribuição das aflatoxinas nas frações granulométricas foram utilizadas, de cada amostra, a fração maior ou igual a 4,5 $\mathrm{mm}$, (subamostra A), mais as fração correspondente à partículas menores que $4,5 \mathrm{~mm}$. As subamostras $B$, foram utilizadas no estudo de distribuição da contaminação em frações separadas visualmente como descrito no item 4.5.

As subamostras $A$, foram pesadas e preparadas para análise de aflatoxinas. O preparo para análise de aflatoxinas consistiu-se primeiro em triturar e subamostrar todo material de cada subamostra $A$ em moinho subamostrador "Romer Analytical Sampling Mill". O material obtido na subamostra do moinho foi posteriormente moído em moinho de martelo até obtenção de granulometria de 20 "mesh", para melhor adequação à extração de aflatoxinas.

No momento da análise, cada subamostra foi manualmente bem homogeneizada e foram retiradas duas amostras analíticas de $50 \mathrm{~g}$ cada, para a análise em duplicata).

As frações de partículas menores que $4,5 \mathrm{~mm}$ foram pesadas e, também, preparadas para análise de aflatoxinas. Entretanto, devido ao peso reduzido dessa fração em cada amostra o preparo consistiu em moer todo o material até obtenção de granulometria de 20 "mesh", em moinho do tipo martelo. No momento da análise, cada amostra foi bem homogeneizada manualmente e, então, foram retiradas duas amostras analíticas de $15 \mathrm{~g}$. Em caso de insuficiência de material, era retirada apenas uma amostra.

\subsection{Avaliação da distribuição das aflatoxinas em grãos separados visualmente.}

Para avaliação da distribuição da contaminação com aflatoxinas em grãos separados visualmente, as trinta subamostras $B$, anteriormente separadas do material com granulometria $\geq 4,5 \mathrm{~mm}$, foram utilizadas. 
Como o objetivo deste teste foi verificar a distribuição da contaminação com aflatoxinas entre os grãos visualmente sadios e não sadios, presente sobre uma amostra equivalente àquela obtida na amostra de classificação, ou seja, com granulometria $\geq 5 \mathrm{~mm}$, todas as amostras $B$ foram novamente passadas por uma peneira, desta vez com crivos redondos de $5 \mathrm{~mm}$ de diâmetro, para retirada do material com granulometria menor que $5 \mathrm{~mm}$ e que estivesse porventura presente nas amostras.

Após passagem pela peneira os grãos ou pedaços de grãos maiores ou iguais a $5,0 \mathrm{~mm}$, foram, então, separados visualmente em grãos aparentemente sadios e grãos com algum tipo de defeito (não sadios).

Os grãos sadios eram constituídos de grãos regulares, conforme descrito no item 4.2.2.

Os grãos não sadios eram constituídos de grãos ardidos, avariados, brotados, carunchados, chochos e quebrados, conforme descrito também no ítem 4.2.2.

As frações de grãos sadios e não sadios, de cada amostra, foram pesados e preparados para análise de aflatoxinas.

Na preparação cada uma das frações foi triturada e subamostrada em moinho subamostrador "Romer Analytical Sampling Mill", sendo a subamostra obtida posteriormente moída em moinho de martelo até obtenção de granulometria de 20 "mesh" $(0,84 \mathrm{~mm})$. A partir das subamostras moídas foram então retiradas, no momento da análise e após homogeneização manual, duas amostras analíticas de $50 \mathrm{~g}$ cada para análise em duplicata.

O fluxograma da metodologia aplicada na obtenção e preparo das amostras para este estudo é mostrado na Figura 1. 


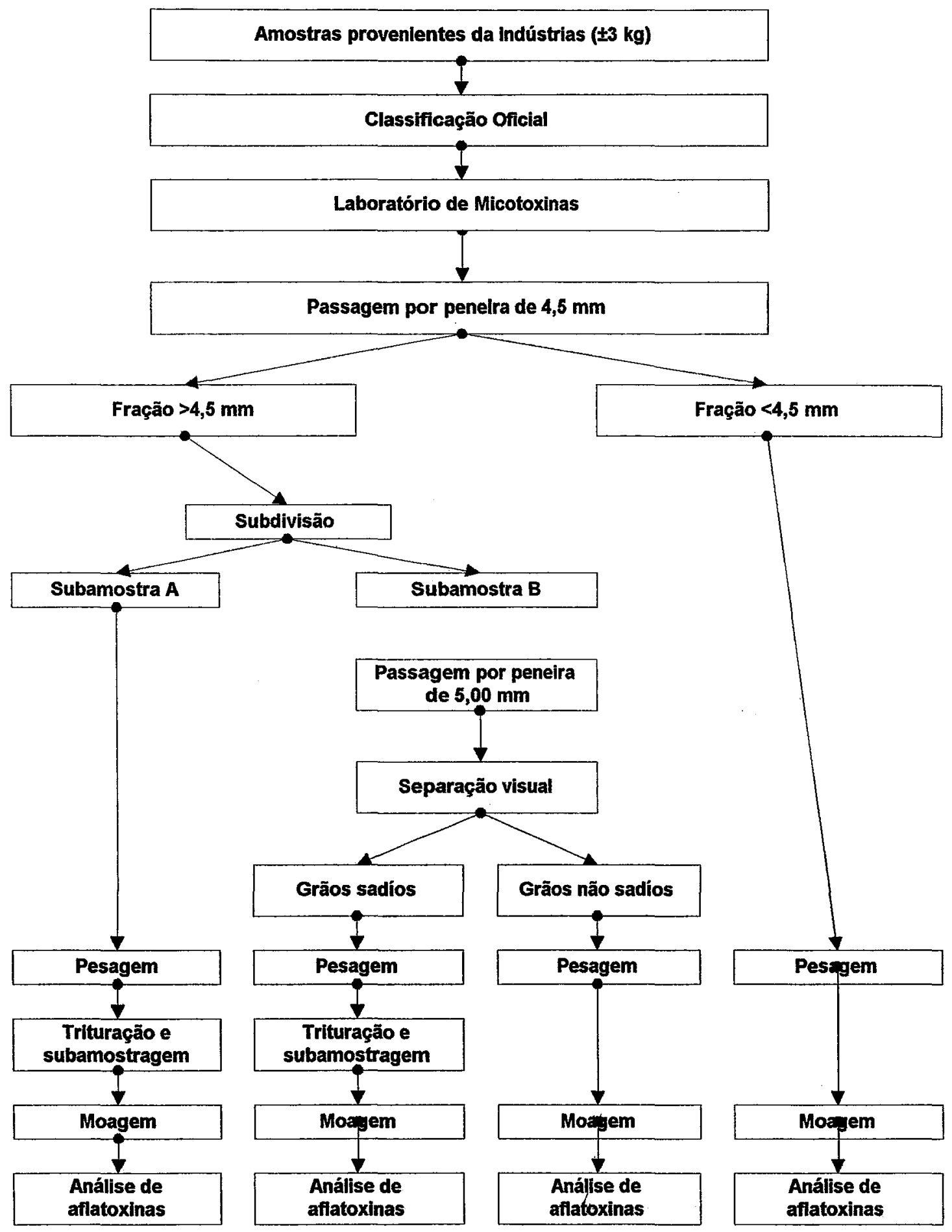

Fig. 1. Fluxograma da metodologia para avaliação da distribuiçăo de aflatoxinas nas frações de milho contaminado. 


\subsection{Análise das aflatoxinas}

Para a extração das aflatoxinas, a partir da amostra analítica, foi empregada a metodologia de Soares \& Rodriguez-Amaya (1989).

\subsubsection{Para a fração maior que $4,5 \mathrm{~mm}$, grãos sadios e não sadios.}

O procedimento de análise das aflatoxinas nas amostras analíticas, provenientes das subamostras $A$, do estudo de distribuição da contaminação em frações granulométricas e das frações de grãos sadios e não sadios, do estudo de distribuição da contaminação em frações separadas visualmente, foi semelhante e executado em duplicata.

Para extração das aflatoxinas do substrato cada amostra analítica de $50 \mathrm{~g}$ foi transferida para um erlenmeyer de $500 \mathrm{~m}$ e extraída com $270 \mathrm{ml}$ de metanol e $30 \mathrm{ml}$ de uma solução de cloreto de potássio a $4 \%$, em agitador mecânico por 30 minutos.

Em seguida, o extrato foi filtrado em papel de filtro qualitativo e do filtrado obtido, tomou-se uma alíquota de $150 \mathrm{ml}$ em um béquer de $600 \mathrm{ml}$ à qual foram adicionados $150 \mathrm{ml}$ de sulfato de amônea $30 \%$ e $5 \mathrm{~g}$ de celite. $\mathrm{Em}$ seguida, a mistura foi filtrada e do filtrado foram tomados $150 \mathrm{ml}$, os quais foram transferidos para um funil de separação de $500 \mathrm{ml}$.

Para extração e purificação das aflatoxinas do filtrado, foram utilizadas duas bipartições com $10 \mathrm{ml}$ de clorofórmio cada. Após a adição do clorofórmio, agitou-se vagarosamente por 3 minutos, aguardou-se a separação das fases e coletou-se a fase clorofórmica. As fases clorofórmicas da primeira e segunda bipartição foram reunidas em tubos tipo de centrífuga. 
O volume de clorofórmio foi então agitado por 15 segundos, em agitador de tubos Vortex, sendo em seguida retirado uma alíquota de $10 \mathrm{ml}$ que foi transferida para um frasco de vidro de volume aproximado de $15 \mathrm{ml}$.

Em seguida, o extrato foi evaporado até a secura em banho-maria na temperatura de $50^{\circ} \mathrm{C}$ sob fluxo de nitrogênio. O material seco foi redissolvido em benzeno+acetonitrila $(98+2)$ e agitado, em agitador de tubos Vortex, por 30 segundos.

\subsubsection{Para a fração menor que $4,5 \mathrm{~mm}$}

A extração das aflatoxinas na fração granulométrica menor que 4,5 $\mathrm{mm}$ foi diferente da análise dos demais materiais em função do reduzido peso dessa fração nas amostras estudadas. As analises foram, quando havia material suficiente, executadas em duplicata.

Assim, para extração das aflatoxinas do substrato, uma amostra analítica de $15 \mathrm{~g}$ foi transferida para um erlenmeyer de $250 \mathrm{ml}$ e extraída com 81 $\mathrm{ml}$ de metanol e $9 \mathrm{ml}$ de uma solução de cloreto de potássio a $4 \%$, em agitador mecânico por 30 minutos. Em seguida o extrato foi filtrado em papel de filtro qualitativo. Do filtrado obtido, tomou-se uma alíquota de $60 \mathrm{ml}$ em um béquer de $400 \mathrm{ml}$ à qual foram adicionados $60 \mathrm{ml}$ de sulfato de amônio $30 \%$ e $5 \mathrm{~g}$ de celite. Em seguida, a mistura foi filtrada e do filtrado foram retirados $60 \mathrm{ml}$, os quais foram transferidos para um funil de separação de $250 \mathrm{ml}$.

Para extração e purificação das aflatoxinas do filtrado, foram utilizadas duas bipartições com $10 \mathrm{ml}$ de clorofórmio cada. Após a adição do clorofórmio, agitou-se vagarosamente por 3 minutos, aguardou-se a separação das fases e coletou-se a fase clorofórmica. As fases clorofórmicas da primeira e segunda bipartição foram reunidas em tubos tipo de centrifuga. 
O volume de clorofórmio foi então agitado por 15 segundos, em agitador de tubos Vortex, sendo em seguida retirado uma alíquota de $10 \mathrm{ml}$ que foi transferida para um frasco de vidro de volume aproximado de $15 \mathrm{ml}$.

Em seguida, o extrato foi evaporado até a secura em banho-maria na temperatura de $50^{\circ} \mathrm{C}$ sob fluxo de nitrogênio. O material seco foi redissolvido em benzeno+acetonitrila $(98+2)$ e agitado, em agitador de tubos Vortex, por 30 segundos.

\subsection{Detecção das aflatoxinas}

A detecção das aflatoxinas foi realizada por cromatografia em camada delgada (CCD), utilizando-se cromatofolhas de silica-gel 60, da marca Merck, empregando-se desenvolvimento bidirecional.

O esquema de desenvolvimento da placa bidirecional está representado na Figura 2.

$\mathrm{Na}$ posição A foi aplicada a alíquota de10 $\mu \mathrm{L}$ da amostra; na posição $B, 3 \mu \mathrm{L}$ do padrão de aflatoxinas e, na posição $C, D$ e $E$ foram aplicados 3, 4 e $6 \mu \mathrm{L}$, respectivamente, dos padrões das aflatoxinas. As placas foram desenvolvidas primeiramente na posição 1 (Figura 2), empregando o sistema de solventes clorofórmio + acetona $(9+1)$, depois retiradas da cuba, deixadas secar em capela e colocadas para desenvolver na $2^{a}$ direção no sistema de solventes tolueno + acetato de etila + ácido fórmico + clorofórmio (5+4+1+4).

A detecção das aflatoxinas foi realizada comparando-se o desenvolvimento do extrato das amostras com o desenvolvimento do extrato do padrão das aflatoxinas.

Amostras que mostravam manchas fluorescentes com cor, tonalidade e posição após desenvolvimento, semelhantes aos padrões foram consideradas provavelmente contaminadas com aflatoxina. 
Nas amostras com contaminação provável um procedimento de confirmação da identidade das aflatoxinas foi aplicado.

A confirmação das aflatoxinas foi efetuada por derivação química, utilizando-se para isso o ácido trifluoracético, segundo a metodologia de Scott (1990), item 985.17.

Foram utilizadas duas soluções trabalho, dissolvidas em benzeno+acetonitrila (98+2). Uma tinha concentração menor e era utilizada para detectar pequenas concentrações das toxinas. A outra, apresentava concentração maior e era utilizada para detectar concentrações altas. As respectivas concentrações estão apresentadas na Tabela 2 abaixo.

Tabela 2. Concentração dos padrões empregados para detecção e quantificação das aflatoxinas.

\begin{tabular}{cc}
\hline Padrão menos concentrado & Padrão mais concentrado \\
\hline $\mathrm{B} 1=0,174 \mu \mathrm{g} / \mathrm{ml}$ & $\mathrm{B} 1=0,3482 \mu \mathrm{g} / \mathrm{ml}$ \\
$\mathrm{B} 2=0,1064 \mu \mathrm{g} / \mathrm{ml}$ & $\mathrm{B} 2=0,1330 \mu \mathrm{g} / \mathrm{ml}$ \\
$\mathrm{G} 1=0,1677 \mu \mathrm{g} / \mathrm{ml}$ & $\mathrm{G} 1=0,3350 \mu \mathrm{g} / \mathrm{ml}$ \\
$\mathrm{G} 2=0,1047 \mu \mathrm{g} / \mathrm{ml}$ & $\mathrm{G} 2=0,1308 \mu \mathrm{g} / \mathrm{ml}$ \\
\hline
\end{tabular}

Em função da alíquota de extrato da amostra aplicada, da concentração e alíquota de padrăo aplicado e da quantidade de interferentes presentes neste tipo de substrato, o limite de detecção observado para metodologia foi de $1 \mu \mathrm{g} / \mathrm{kg}$. 


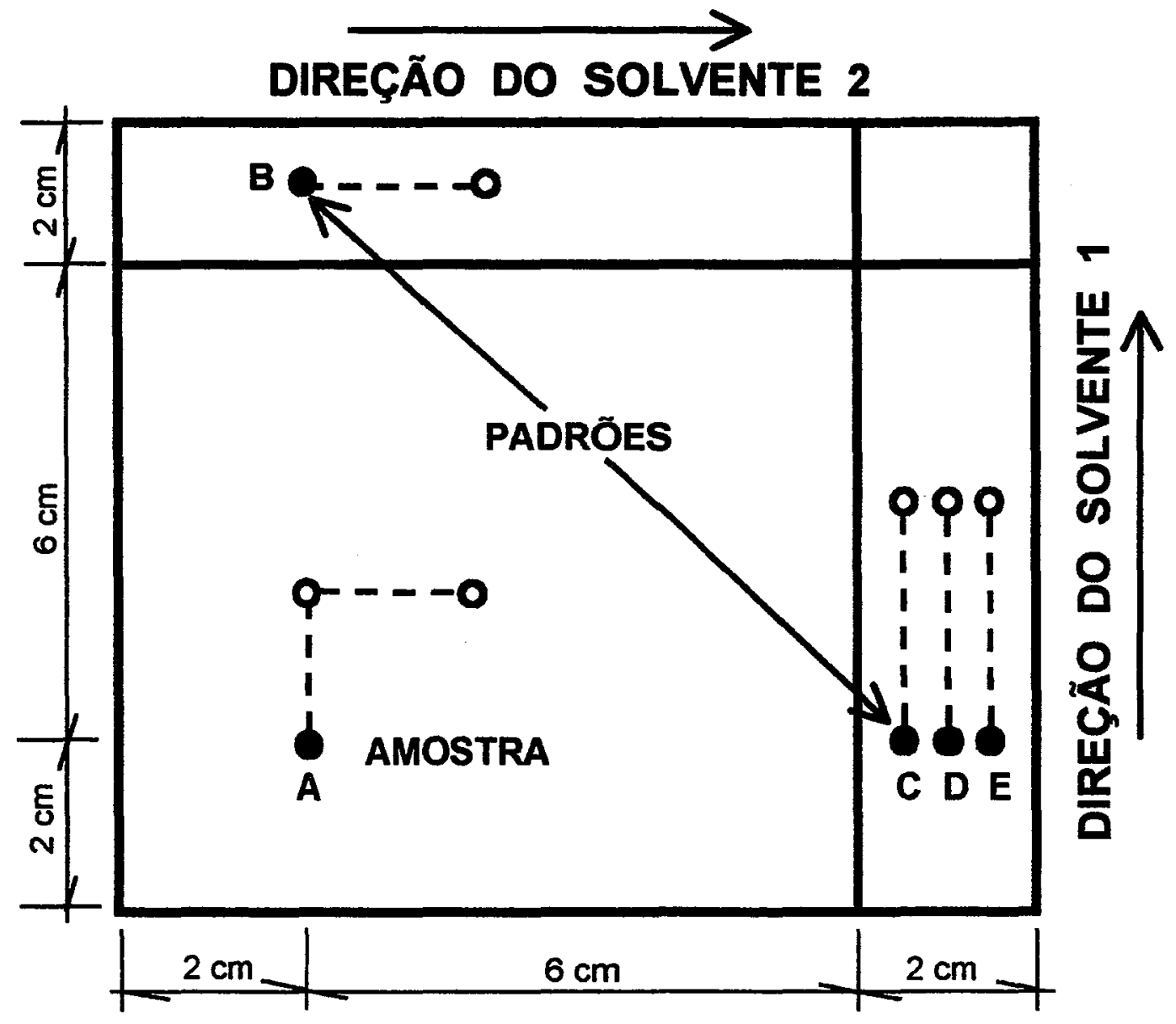

Figura 2. Esquema da divisão da placa de cromatografia bidirecional e disposição das alíquotas do padrão e extrato da amostra. 


\subsection{Quantificação}

A quantificação foi feita através da comparação visual da intensidade da fluorescência da amostra com a do padrão quantitativo.

Em função do limite de detecção observado neste estudo adotouse para melhor segurança dos resultados o limite de quantificação de $1 \mu \mathrm{g} / \mathrm{kg}$

O cálculo da concentração das aflatoxinas foi efetuado, após a comparação das intensidades das aflatoxinas presentes no extrato da amostra com as aflatoxinas das alíquotas dos padrões aplicados.

Para o cálculo aplicou-se a seguinte fórmula:

$$
\frac{Y . S . V}{X . W}=\mu g / k g \text { de toxina ou } \mathrm{ppb}
$$

onde,

$\mathrm{Y}=$ concentração do padrão em $\mu \mathrm{g} / \mathrm{ml}$;

$S=$ microlitros do padrão da toxina com fluorescência equivalente à da amostra;

$V=$ microlitros do volume final do extrato da amostra;

$X=$ microlitros aplicados do extrato final;

$W=$ peso da amostra, em gramas, no extrato final. 


\subsection{Delineamento Estatístico}

O delineamento estatístico foi o inteiramente casualisado com trinta repetições.

Para verificar a existência de diferença estatística entre os valores de contaminação das frações granulométricas $<4,5$ e $\geq 4,5 \mathrm{~mm}$ e dos grãos sadios e não sadios, os dados foram transformados para logaritmo $(x+0,5)$ e a análise estatística foi feita utilizando o teste $F$ da análise de variância.

Para a análise estatística foram utilizados os níveis de contaminação das médias das duplicatas das análises.

As análises estatísticas foram feitas utilizando-se do SANEST Sistema de Análise Estatística para Microcomputadores (Machado \& Zonta, 1990).

O teste $\mathrm{F}$ da análise de variância foi utilizado para comparação dos resultados das médias de contaminação obtidas nas frações granulométricas (<4,5 e $\geq 4,5 \mathrm{~mm}$ ) e grãos sadios e não sadios.

Foram também determinados índices de correlação entre os grupos de defeitos - grãos ardidos, queimados e brotados; grãos avariados e impurezas e matéria estranha - com os niveis de contaminação estimados para as frações estudadas ( $<4,5$ e $\geq 4,5 \mathrm{~mm}$, sadios e não sadios), para determinar significância estatística entre estes parâmetros. 


\section{RESULTADOS E DISCUSSÃO}

\subsection{Classificação das amostras}

Analisando os dados das características qualitativas das amostras estudadas e sua classificação por tipos segundo as normas oficiais brasileiras (Brasil, 1976), mostrados na Tabela 3, notamos a maior incidência de amostras tipo 3 e AP (10 e 13 amostras, respectivamente); os tipos 1 e 2, ocorreram em menor número (3 e 4 amostras, respectivamente). Apesar do número reduzido de dados, isto sugere uma probabilidade maior de encontrarmos amostras do tipo 3 ou AP contaminadas com aflatoxinas. 
Tabela 3. Propriedades físicas e classificação por tipo (Normas Brasileiras) das amostras de milho.

\begin{tabular}{|c|c|c|c|c|c|}
\hline Amostra & $\begin{array}{c}\text { Umidade } \\
\%\end{array}$ & $\begin{array}{c}\text { Avariados } \\
\%\end{array}$ & $\begin{array}{c}\text { Ardidos } \\
\%\end{array}$ & $\begin{array}{c}\text { Impurezas } \\
\%\end{array}$ & $\begin{array}{c}\text { Classificação por } \\
\text { tipo }^{a}\end{array}$ \\
\hline 1 & 13,70 & 6,40 & 3,10 & 1,50 & 2 \\
\hline 2 & 11,10 & 7,00 & 2,40 & 3,30 & AP \\
\hline 3 & 13,70 & 8,20 & 3,10 & 2,40 & 3 \\
\hline 4 & 13,40 & 9,50 & 3,40 & 3,00 & 3 \\
\hline 5 & 13,90 & 5,00 & 3,30 & 1,40 & 2 \\
\hline 6 & 12,70 & 9,50 & 6,60 & 3,20 & $A P$ \\
\hline 7 & 13,30 & 7,90 & 2,80 & 3,10 & AP \\
\hline 8 & 12,20 & 7,90 & 3,60 & 4,00 & AP \\
\hline 9 & 14,90 & 11,60 & 3,40 & 3,10 & AP \\
\hline 10 & 12,40 & 8,20 & 2,60 & 1,90 & 2 \\
\hline 11 & 12,60 & 10,00 & 1,90 & 1,50 & 1 \\
\hline 12 & 13,20 & 7,40 & 4,00 & 2,50 & 3 \\
\hline 13 & 13,20 & 10,30 & 3,10 & 3,40 & $A P$ \\
\hline 14 & 13,80 & 8,20 & 3,10 & 3,00 & 3 \\
\hline 15 & 13,40 & 6,80 & 2,30 & 1,30 & 1 \\
\hline 16 & 13,40 & 10,40 & 2,40 & 2,80 & 3 \\
\hline 17 & 13,10 & 6,10 & 2,10 & 3,70 & AP \\
\hline 18 & 12,00 & 11,90 & 3,90 & 3,30 & AP \\
\hline 19 & 12,20 & 11,70 & 3,20 & 4,40 & $A P$ \\
\hline 20 & 11,80 & 7,40 & 1,40 & 2,00 & 2 \\
\hline 21 & 12,80 & 10,00 & 2,20 & 3,50 & AP \\
\hline 22 & 11,70 & 9,20 & 1,00 & 1,30 & 1 \\
\hline 23 & 12,90 & 10,60 & 2,00 & 3,40 & $A P$ \\
\hline 24 & 12,70 & 10,40 & 1,30 & 2,70 & 3 \\
\hline 25 & 12,40 & 20,40 & 4,40 & 3,10 & AP \\
\hline 26 & 12,80 & 9,90 & 0,80 & 2,40 & 3 \\
\hline 27 & 13,60 & 7,20 & 3,90 & 2,70 & 3 \\
\hline 28 & 12,70 & 10,60 & 0,70 & 3,90 & $A P$ \\
\hline 29 & 12,70 & 11,20 & 2,70 & 2,70 & 3 \\
\hline 30 & 12,0 & 17,10 & 7,20 & 2,60 & 3 \\
\hline
\end{tabular}

a - Classificação do milho em tipos 1, 2, 3 e AP de acordo com a percentagem de defeitos observados nos lotes. 


\subsection{Distribuição das aflatoxinas nas frações separadas granulometricamente.}

Os resultados referentes à distribuição das aflatoxinas nas frações $\geq 4,5 \mathrm{~mm}$ e $<4,5 \mathrm{~mm}$, bem como a contaminação estimada das amostras avaliadas, estão apresentados na Tabela 4

Para verificar a existência de diferença estatística entre os valores de contaminação observados entre as frações, os dados foram transformados em $\log (x+0,5)$ e as análises foram feitas utilizando o teste $F$ da análise de variância.

Foi verificado que os niveis de aflatoxinas da fração $<4,5 \mathrm{~mm}$ foram estatisticamente maiores que o da fração $\geq 4,5 \mathrm{~mm}$ ao nível de significância de $5 \%$ (Tabelas 4 e 5). Entretanto a contaminação a fração $\geq 4.5 \mathrm{~mm}$, em 10 amostras (33\%), foi maior que a fração $<4,5 \mathrm{~mm}$. Isto sugere uma variação, de lote para lote de milho, no comportamento dos níveis de contaminação a serem observados entre as frações granulométricas estudadas. Em geral a fração $<4,5 \mathrm{~mm}$ pode apresentar-se com um nível de contaminação mais elevado do que a fração $\geq 4,5 \mathrm{~mm}$, mas em alguns lotes a fração $\geq 4,5 \mathrm{~mm}$ pode-se apresentar com os níveis mais alto de contaminação.

Entretanto, as percentagens de participação das frações na contaminação total estimada para cada amostra, tendo como base o nível de contaminação e o peso da fração, apresentados na Tabela 4 , mostram que a fração $\geq 4,5 \mathrm{~mm}$ sempre foi a que mais contribuiu para contaminação total tendo apresentado em 29 amostras estudadas um nível de participação de 96,5\% contra $3,5 \%$ da fração $<4,5 \mathrm{~mm}$. Mesmo que a fração $<4,5 \mathrm{~mm}$ tenha uma menor participação média de aflatoxinas $(84,8 \mu \mathrm{g} / \mathrm{kg}$ contra $204,0 \mu \mathrm{g} / \mathrm{kg}$ da fração $<4,5 \mathrm{~mm}$ ), a influência da fração $\geq 4,5 \mathrm{~mm}$ foi muito grande devido ao seu maior peso. 
Tais resultados mostram que a retirada da fração $<4,5 \mathrm{~mm}$ das amostras não contribuiria para a diminuição do nível de contaminação total das amostras como foi concluído também por Shotwell et al. (1972) e Brekke et al. (1975).

As percentagens dos grupos de defeitos: a) grãos ardidos, queimados e brotados, b) grãos avariados e c) impurezas/matéria estranha, encontrados nas amostras mostraram um índice de correlação com os niveis de contaminação estimados para amostra (Tabela 4) de $r=0,50,0,62$ e 0,25, respectivamente. Estes índices de 0,50 e 0,62 foram estatisticamente significativos $(p<1 \%)$ e o último indice de 0,25 não foi significativo ( $p>5 \%$ ). Entretanto, outros estudos em nosso laboratório, ainda não publicados, não mostraram correlação significativa entre estes parâmetros. Portanto o uso dos indices de classificação para estimativa do nivel de contaminação com aflatoxinas deve ser melhor estudado. 
Tabela 4. Valores médios de aflatoxinas $B_{1}+B_{2}+G_{1}+G_{2}$, em $\mu \mathrm{g} / \mathrm{kg}$, das duplicatas das frações estudadas, peso da fração e contribuição da fração para o nivel de contaminação da amostra total.

\begin{tabular}{|c|c|c|c|c|c|c|c|c|c|c|}
\hline \multirow[t]{2}{*}{ Amostra } & \multicolumn{4}{|c|}{$\begin{array}{l}\text { Fracão A } \\
>4,5 \mathrm{~mm}\end{array}$} & \multicolumn{4}{|c|}{$\begin{array}{l}\text { Fracão B } \\
<4,5 \mathrm{~mm}\end{array}$} & \multicolumn{2}{|c|}{ Amostra Total } \\
\hline & $\begin{array}{c}\text { Peso } \\
\text { (g) }\end{array}$ & $(\%)^{2}$ & $\begin{array}{l}\text { Cont. }^{1} \\
\text { (ng/g) }\end{array}$ & $(\%)^{3}$ & $\begin{array}{l}\text { Peso } \\
\text { (g) }\end{array}$ & $(\%)^{2}$ & $\begin{array}{l}\text { Cont. } \\
\text { (ng/g) }\end{array}$ & $(\%)^{3}$ & $\begin{array}{l}\text { Peso } \\
\text { (g) }\end{array}$ & $\begin{array}{l}\text { Cont. } \\
\text { Est. }^{4}\end{array}$ \\
\hline 1 & 2.009 & 98 & 44 & 99 & 37 & 2 & 34 & 1 & 2.047 & 44 \\
\hline 2 & 1.244 & 95 & 4 & 93 & 66 & 5 & 6 & 7 & 1.311 & 4 \\
\hline 3 & 1.225 & 98 & 45 & 96 & 30 & 2 & 77 & 4 & 1.255 & 46 \\
\hline 4 & 1.804 & 96 & 94 & 97 & 67 & 4 & 89 & 3 & 1.872 & 94 \\
\hline 5 & 1.663 & 98 & 62 & 97 & 32 & 2 & 97 & 3 & 1.695 & 63 \\
\hline 6 & 1.632 & 97 & 8 & 8 & 46 & 3 & 45 & 14 & 1.678 & 9 \\
\hline 7 & 1.398 & 96 & 97 & 96 & 60 & 4 & 92 & 4 & 1.458 & 97 \\
\hline 8 & 1.483 & 95 & 36 & 96 & 75 & 5 & 33 & 4 & 1.558 & 36 \\
\hline 9 & 1.404 & 94 & 33 & 99 & 90 & 6 & 6 & $i$ & 1.494 & 31 \\
\hline 10 & 1.231 & 95 & 39 & 97 & 68 & 5 & 20 & 3 & 1.299 & 38 \\
\hline 11 & 1.708 & 98 & 18 & 99 & 28 & 2 & 16 & 1 & 1.736 & 18 \\
\hline 12 & 1.549 & 98 & 300 & 98 & 39 & 2 & 242 & 2 & 1.588 & 299 \\
\hline 13 & 1.557 & 96 & 26 & 96 & 66 & 4 & 25 & 4 & 1.623 & 26 \\
\hline 14 & 1.758 & 97 & 58 & 95 & 62 & 3 & 87 & 5 & 1.821 & 59 \\
\hline 15 & 1.399 & 98 & 37 & 98 & 25 & 2 & 49 & 2 & 1.424 & 37 \\
\hline 16 & 1.314 & 97 & 51 & 98 & 36 & 3 & 32 & 2 & 1.349 & 50 \\
\hline 17 & 1.673 & 94 & 31 & 79 & 111 & 6 & 125 & 21 & 1.784 & 37 \\
\hline 18 & 1.575 & 95 & 86 & 89 & 83 & 5 & 206 & 11 & 1.658 & 92 \\
\hline 19 & 1.611 & 98 & 369 & 92 & 36 & 2 & 1422 & 8 & 1.647 & 392 \\
\hline 20 & 1.758 & 96 & 11 & 55 & 68 & 40 & 231 & 45 & 1.827 & 19 \\
\hline 21 & 1.639 & 96 & 52 & 86 & 65 & 4 & 213 & 14 & 1.704 & 58 \\
\hline 22 & 1.681 & 97 & 23 & 91 & 469 & 3 & 87 & 9 & 1.728 & 25 \\
\hline 23 & 1.543 & 94 & 12 & 90 & 93 & 6 & 23 & 10 & 1.637 & 13 \\
\hline 24 & 1.622 & 96 & 14 & 85 & 74 & 4 & 53 & 15 & 1.696 & 16 \\
\hline 25 & 1.560 & 98 & 343 & 93 & 34 & 2 & 1172 & 7 & 1.594 & 360 \\
\hline 26 & 1.563 & 95 & 12 & 81 & 78 & 5 & 56 & 19 & 1.641 & 14 \\
\hline 27 & 1.540 & 98 & 68 & 95 & 29 & 2 & 203 & 5 & 1.569 & 70 \\
\hline 28 & 1.535 & 97 & 113 & 88 & 55 & 3 & 414 & 12 & 1.590 & 123 \\
\hline 29 & 1.682 & 96 & 69 & 93 & 62 & 4 & 135 & 7 & 1.744 & 71 \\
\hline 30 & 1.530 & 98 & 389 & 95 & 38 & 2 & 831 & 5 & 1.569 & 400 \\
\hline Média & 1.563 & 96,5 & 84,8 & 91,7 & 56,7 & 3,5 & 204,0 & 8,3 & 1.620 & 88,0 \\
\hline
\end{tabular}

1 - Total de Aflatoxinas na fração $\left(B_{1}+B_{2}+G_{1}+G_{2}\right)$.

2 - Participação relativa em peso da fração.

3 - Participação relativa da fração na contaminação da amostra total.

4 - Contaminação Estimada 
Tabela 5. Quadro de análise da variância.

\begin{tabular}{lccccc}
\hline Causas da Variação & G.L. & S.Q. & Q.M. & Valor F & Prob.>F \\
\hline Fração & 1 & 6,7501433 & 6,7501433 & 4,8349 & 0,02999 \\
Resíduo & 58 & 80,9746390 & 1,3961145 & & \\
\hline Total & 59 & 87,7247823 & & & \\
\hline
\end{tabular}

Média geral $=4,171977$

Coeficiente de variação $=28,322 \%$

Tabela 6. Médias do fator fração

\begin{tabular}{ccccc}
\hline Num. Trat. & Nome & Num. Repet. & Médias & Médias originais \\
\hline 1 & FA & 30 & $4,507391 \mathbf{a}$ & 90,184870 \\
2 & FB & 30 & $3,836563 \mathbf{b}$ & 45,865842 \\
\hline
\end{tabular}

$\mathrm{FA}=$ Fração $<4,5 \mathrm{~mm}$

$\mathrm{FB}=$ Fração $>4,5 \mathrm{~mm}$

\subsection{Distribuição das aflatoxinas nas frações separadas visualmente.}

Os resultados referentes à contaminação com aflatoxinas nas frações estudadas bem como a contaminação total estimada para cada amostra encontram-se na Tabela 7. Para verificar a existência de diferença estatística entre os valores de contaminação observados entre os tipos de grãos sadios e não sadios, os dados foram transformados em $\log (x+0,5)$ e as análises foram feitas utilizando o teste $F$ da análise de variância.

Os niveis de contaminação dos grãos não sadios variou de 23 a $1365 \mu \mathrm{g} / \mathrm{kg}$ e foi maior que os grãos sadios ( $p<1 \%$ - Tabelas 8 e 9) que variou 
de não detectado a $126 \mu \mathrm{g} / \mathrm{kg}$. Os níveis de contaminação dos grãos sadios foram menores que $20 \mu \mathrm{g} / \mathrm{kg}$, o máximo nivel permitido no Brasil (Brasil, 1996), em $87 \%$ das amostras e $13 \%$ foi maior que este limite. Além dos niveis estarem abaixo do limite, eles foram bem menores que dos grãos não sadios. Todas as amostras de grãos não sadios apresentaram contaminação maior que $20 \mu \mathrm{g} / \mathrm{kg}$.

A fração de grãos não sadios representou uma média de 14 a $35 \%$ do total de grãos das amostras avaliadas. A correlação entre as percentagens de grãos não sadios e a contaminação com aflatoxinas foi muito baixo $(r=0,25$; $p>5 \%$ ), sugerindo, portanto, que não há correlação entre estes parâmetros.

$\mathrm{Na}$ Tabela 7 vemos que a participação dos grãos sadios no peso total das amostras foi maior que dos grãos não sadios (média de $80 \%$ contra $20 \%$ dos não sadios). Embora essa fração tenha apresentado contaminação, como mostraram também os trabalhos de Shotwell et al. (1974) e Brekke et al.(1975), esta ocorreu em níveis menores apresentando a média de $15 \mu \mathrm{g} / \mathrm{kg}$ contra a média de $271 \mu \mathrm{g} / \mathrm{kg}$ para os grãos não sadios. Quanto à participação relativa da fração na contaminação total da amostra pode-se verificar que a fração de grãos não sadios contribuiu com $84 \%$ da contaminação total estimada enquanto os grãos sadios com $16 \%$.

Assim, com base nos dados obtidos nas condições deste experimento, a retirada da fração de grãos não sadios, embora em menor proporção, porém mais contaminada, contribuiria para uma redução da contaminação da amostra aos niveis permitidos pela legislação em $87 \%$ das amostras, diferindo dos dados de Shotwell et al. (1972) e Shotwell et al. (1974).

Os dados qualitativos das amostras, separados nos seguintes grupos, conforme a Tabela 3: a) grãos ardidos, queimados e brotados; b) grãos avariados e c) impurezas/matéria estranha mostraram um indice de correlação (r) com os niveis de contaminação estimados para as amostras de $r=0,51,0,52$ e 0,14 , respectivamente. Os valores de $r$ para os grãos avariados e ardidos foram significativos $(p<1 \%)$, quando se fez o teste de significância para os 
valores de $r$ obtidos, sugerindo haver uma correlação positiva entre a porcentagem destes tipos de grãos e os níveis de contaminação. Entretanto, dados obtidos pela equipe do laboratório (ainda não publicados) não mostram correlação entre estes valores sugerindo que o uso dos índices de classificação para estimativa do nível de contaminação das amostras deve ser melhor estudado. Já o valor de $r$ obtido para as impurezas/matéria estranha não apresentou correlação com o nível de contaminação estimado das amostras $(p>5 \%)$. 
Tabela 7. Valores médios de aflatoxinas $B_{1}+B_{2}+G_{1}+G_{2}$, em $\mu \mathrm{g} / \mathrm{g}$, das duplicatas das frações estudadas, peso da fração e contribuição da fração para 0 nivel de contaminação da amostra total.

\begin{tabular}{|c|c|c|c|c|c|c|c|c|c|c|}
\hline \multirow[t]{2}{*}{ Amostra } & \multicolumn{4}{|c|}{$\begin{array}{c}\text { Fracão A } \\
\text { Sadios }\end{array}$} & \multicolumn{4}{|c|}{$\begin{array}{c}\text { Fracão B } \\
\text { Não sadios }\end{array}$} & \multicolumn{2}{|c|}{ Amostra Total } \\
\hline & $\begin{array}{c}\text { Peso } \\
\text { (g) }\end{array}$ & $(\%)^{2}$ & $\begin{array}{l}\text { Cont. }^{1} \\
\text { (ng/g) }\end{array}$ & $(\%)^{3}$ & $\begin{array}{c}\text { Peso } \\
\text { (g) }\end{array}$ & $(\%)^{2}$ & $\begin{array}{c}\text { Cont. } \\
\text { (ng/g) }\end{array}$ & $(\%)^{3}$ & $\begin{array}{c}\text { Peso } \\
\text { (g) }\end{array}$ & $\begin{array}{l}\text { Cont. } \\
\text { Est. }\end{array}$ \\
\hline 1 & 1.471 & 83 & 33 & 47 & 301 & 17 & 183 & 53 & 1.773 & 58 \\
\hline 2 & 1.008 & 86 & N.D. & 0 & 166 & 14 & 23 & 100 & 1.174 & 3 \\
\hline 3 & 1.025 & 85 & 28 & 47 & 176 & 15 & 181 & 53 & 1.201 & 50 \\
\hline 4 & 1.415 & 86 & 19 & 38 & 239 & 14 & 180 & 62 & 1.654 & 42 \\
\hline 5 & 1.194 & 79 & 4 & 4 & 323 & 21 & 351 & 96 & 1.517 & 78 \\
\hline 6 & 1.206 & 82 & 3 & 12 & 263 & 18 & 98 & 88 & 1.468 & 20 \\
\hline 7 & 977 & 77 & N.D. & 0 & 291 & 23 & 346 & 100 & 1.269 & 79 \\
\hline 8 & 1.100 & 81 & 7 & 27 & 259 & 19 & 80 & 73 & 1.359 & 21 \\
\hline 9 & 987 & 78 & 10 & 21 & 285 & 22 & 128 & 79 & 1.272 & 36 \\
\hline 10 & 924 & 82 & 5 & 14 & 208 & 18 & 136 & 86 & 1.132 & 29 \\
\hline 11 & 1.347 & 83 & 4 & 16 & 280 & 17 & 100 & 84 & 1.627 & 20 \\
\hline 12 & 1.087 & 80 & 12 & 3 & 280 & 20 & 1.36 & 97 & 1.366 & 289 \\
\hline 13 & 1.161 & 83 & 3 & 26 & 243 & 17 & 41 & 74 & 1.403 & 10 \\
\hline 14 & 1.222 & 73 & 4 & 5 & 454 & 27 & 186 & 95 & 1.676 & 53 \\
\hline 15 & 1.090 & 84 & 5 & 9 & 207 & 16 & 271 & 91 & 1.296 & 47 \\
\hline 16 & 948 & 80 & 8 & 24 & 231 & 20 & 104 & 76 & 1.180 & 27 \\
\hline 17 & 1.225 & 78 & 5 & 16 & 338 & 22 & 94 & 84 & 1.563 & 24 \\
\hline 18 & 1.172 & 80 & 10 & 7 & 291 & 20 & 538 & 93 & 1.463 & 115 \\
\hline 19 & 1.032 & 68 & 104 & 23 & 480 & 32 & 742 & 77 & 1.512 & 306 \\
\hline 20 & 1.327 & 82 & 6 & 14 & 286 & 18 & 169 & 86 & 1.613 & 35 \\
\hline 21 & 1.190 & 80 & 4 & 5 & 296 & 20 & 277 & 95 & 1.487 & 58 \\
\hline 22 & 1.315 & 84 & 8 & 14 & 242 & 16 & 262 & 86 & 1.557 & 48 \\
\hline 23 & 1.178 & 81 & N.D. & 0 & 285 & 19 & 62 & 100 & 1.463 & 12 \\
\hline 24 & 1.263 & 83 & N.D. & 0 & 254 & 17 & 84 & 100 & 1.517 & 14 \\
\hline 25 & 895 & 63 & 126 & 35 & 535 & 37 & 391 & 65 & 1.430 & 225 \\
\hline 26 & 1.218 & 84 & 4 & 37 & 239 & 16 & 35 & 63 & 1.457 & 9 \\
\hline 27 & 1.101 & 77 & 8 & 18 & 333 & 23 & 120 & 82 & 1.434 & 34 \\
\hline 28 & 1.117 & 79 & 12 & 14 & 291 & 21 & 276 & 86 & 1.408 & 67 \\
\hline 29 & 1.250 & 81 & 3 & 3 & 298 & 19 & 376 & 97 & 1.548 & 75 \\
\hline 30 & 926 & 65 & 14 & 3 & 501 & 35 & 918 & 97 & 1.427 & 331 \\
\hline Média & 1.146 & 80 & 15 & 16 & 296 & 20 & 271 & 84 & 1.441 & 74 \\
\hline
\end{tabular}

1 - Total de Aflatoxinas na fraçao $\left(B_{1}+B_{2}+G_{1}+G_{2}\right)$.

2 - Participação relativa em peso da fração.

3 - Participação relativa da fração na contaminação da amostra total.

4 - Contaminação Estimada 
Tabela 8. Quadro de análise da variância.

\begin{tabular}{lccccc}
\hline Causas da Variação & G.L. & S.Q. & Q.M. & Valor F & Prob.>F \\
\hline Tipo & 1 & 165,0928534 & 165,0928534 & 121,7659 & 0,00001 \\
Resíduo & 58 & 78,6376526 & 1,3558216 & & \\
\hline Total & 59 & 243,7305060 & & & \\
\hline
\end{tabular}

Média geral $=3,519069$

Coeficiente de variação $=33,088 \%$

Tabela 9. Médias do fator tipo

\begin{tabular}{ccccc}
\hline Num. Trat. & Nome & Num. Repet. & Médias & Médias originais \\
\hline 1 & T1 & 30 & $1,860290 \mathbf{a}$ & 5,925602 \\
2 & T2 & 30 & $5,177848 \mathbf{b}$ & 176,800888 \\
\hline
\end{tabular}

T1 $=$ grãos sadios

T2 = grãos não sadios 


\section{CONCLUSÕES}

1) A concentração de aflatoxinas entre as frações $<4,5$ ou $\geq 4,5 \mathrm{~mm}$ pode variar de amostra para amostra de milho, entretanto a fração $<4,5 \mathrm{~mm}$ apresentou-se normalmente com maior concentração de aflatoxinas, mostrando que a utilização desse material deve ser criteriosa para evitar-se altas concentrações de aflatoxinas.

2) Devido a participação pequena da fração $<4,5 \mathrm{~mm}$ no peso da amostra esta fração geralmente contribui pouco para contaminação total da amostra. Assim, a segregação do material $<4,5 \mathrm{~mm}$ da amostra original geralmente não produziu um material com menor concentração de aflatoxinas.

3) Os índices de correlação entre as percentagens dos grupos de defeitos definidos pela Classificação Oficial: a) grãos ardidos, queimados e brotados e b) grãos avariados, foram significativos com relação aos niveis de contaminação estimados para as frações granulométricas. Entretanto, diferem de dados ainda não publicados (obtidos pela equipe do Laboratório de Micotoxinas) e portanto devem ser melhor estudados.

4) Os grãos sadios apresentaram menor contaminação que os não sadios em todas as amostras.

5) Embora a participação dos grãos não sadios tenha sido pequena no peso da amostra, a contaminação dessa fração contribuiu, em média, com $84 \%$ da contaminação estimada das amostras. Portanto a retirada dos grãos não sadios, contribuiria para uma redução da contaminação da amostra. 
6) Os índices de correlação entre as percentagens dos grupos de defeitos definidos pela Classificação Oficial: a) grãos ardidos, queimados e brotados e b) grãos avariados, significativos com relação aos niveis de contaminação estimados para as frações de grãos sadios e não sadios. Entretanto, diferem de dados não publicados (obtidos pela equipe do Laboratório de Micotoxinas) e portanto devem ser melhor estudados. 


\section{REFERÊNCIAS BIBLIOGRÁFICAS}

AMERICAN ASSOCIATION OF CEREAL CHEMISTS. Approved methods of the American Association of Cereal Chemists. 9 ed. Washington, 1995. v.2., 1v.

ABRAMSON, D. Development of molds, mycotoxins and odor in moist cereals during storage. In: CHELKOWSKI, J. Cereal Grain: mycotoxins, fungi and quality in drying and storage. Amsterdam: Elsevier, 1991. cap. 6, p. 119-142.

ALLCROFT, R.; CARNAGHAN, R.B.A. Groundnut toxicity. Aspergillus flavus toxin (aflatoxin) in natural products: preliminary communications. Veterinary Record, v.74, p. 863-864, 1962.

ALLCROFT, R.; ROGERS, H.; LEWIS, G.; NABNEY, J.; BEST, P.E. Metabolism of aflatoxin in sheep: excretion of the "milk toxin" Nature, v.209, n.5019, p. 154-155, 1966.

ALMEIDA, R.M.A. Avaliação dos efeitos agudos produzidos por aflatoxina $\mathrm{B}_{1} \mathrm{em}$ diferentes linhagens de camundongos isogênicos. São Paulo, 1994. 125p. Tese (Doutorado). Instituto de Ciências Biomédicas, Universidade de São Paulo. 
ASPLIN, F.D.; CARNAGHAN, R.B.A. The toxicity of certain groundnut meals for poultry with special reference to their effect on ducklings and chickens. Veterinary Record, v.73, p. 1215-1219, 1961.

BALDISSERA, M.A.; SANTURIO, J.M.; MALLMANN, C.A.; ALMEIDA, C.A.A.; KIPPER, M.; SOUZA JR., C.E.; SANTOS, X.C.; CAMARGO, B.S. Aflatoxinas, zearalenona e ocratoxina $A$ em alimentos resultados de 1987 a 1993. In: CONGRESSO LATINO-AMERICANO DE MICOTOXICOLOGIA 1. ENCONTRO NACIONAL DE MICOTOXINAS 8., Rio de Janeiro, 1994. Anais. Rio de Janeiro: Imprensa Universitária - UFRRJ, 1994. p. 90-94.

BETINA, V. Mycotoxins: chemical, biological and environmental aspects. Amsterdam: Elsevier, 1989. p. 114-150: Aflatoxins, sterigmatocystins and versicolorins.

BRADBURN, N.; BLUNDEN, G.; COKER, R.D.; JEWERS, K. Aflatoxin contamination of maize. Tropical Science, v.33, p. 418-428, 1993.

BRADBURN, N.; COKER, R.D. Aflatoxin contamination in maize. Tropical Science, v.33, n.44, p.418-428, 1993.

BRASIL. Leis, decretos, etc. Ministério da Agricultura. Portaria n. 183, de 21 de março de 1996. Diário Oficial da União, Brasília, 25 de março de 1996. Art 1. Adotar Regulamento Técnico MERCOSUL sobre Limites Máximos de Aflatoxinas. Admissíveis no leite, Amendoim e Milho, aprovado pela Resolução do Grupo Mercado Comum do Sul n. 56/94, de 1 de janeiro de 1996. 
BRASIL. Leis, decretos, etc. Ministério da Agricultura. Portaria $n^{\circ} .845$, de 08 de novembro de 1976. Diário Oficial da União, Brasília, 19 de novembro de 1976. Art 1. Aprovar as especificaçães para a padronização, classificação e comercialização interna do milho.

BRASIL. Leis, decretos, etc. Resolução n. 34/76 da Comissão Nacional de Normas e Padrões para alimentos. Diário Oficial da União, Brasília, 19 de jan. 1977. Seção I, pt. I, p.710. Fixa padrões de tolerância para aflatoxinas em alimentos.

BREKKE, O.L.; PEPLINSKI, A.J.; GRIFFIN Jr., E.L. Cleaning trials for corn containing aflatoxin. Cereal Chemistry, v.52, n.2, p.198-204, 1975.

BRYDEN, W.L.; RAVINDRAN, G.; AMBA, M.T.; GILL, R.J.; BURGES, L.W. Mycotoxin contamination of maize grown in Australia, the Phillippines and Vietnam. In: INTERNATIONAL IUPAC SYMPOSIUM ON MYCOTOXINS AND PHICOTOXINS 9., Rome, 1996. Abstract Book. Rome: Istituto Superiore di Sanitá, 1996. p. 41.

BUTLER, W.H. Aflatoxin. In: PURCHASE, I.F.H. (Ed). Mycotoxins. Amsterdam: Elsevier, 1974. cap 1, p. 1-28.

CALVERT, O.H.; LILLEHOJ, E.B.; KWOLEK, W.F.; ZUBER, M.S. Aflatoxin B and $G_{1}$ production in developing Zea mays kernels from mixed inocula of Aspergillus flavus and A. parasiticus. Phytopathology, n. 68, p. 501-506, 1978.

CARNAGHAN, R.B.A.; HARTLEY, R.D.; O'KELLY, J. Toxicity anf fluorescence properties of the aflatoxins. Nature, n.200, v. 4911, p. 1101, 1963. 
CASTOR, L.L.; MIROCHA, C.J.; CHANG, H.L. Aflatoxin occurrence in maize samples collected in Haitian markets. Plant Disease, v. 71, n. 11, p. 969-971, 1987.

CHRISTENSEN, C.M.; KAUFMANN, H.H. Grain Storage: the role of the fungi in quality loss. Minneapolis: University of Minnesota Press, 1969. $153 \mathrm{p}$.

CHULZE, S.; BERTINETTI, C.; DALCERO, A; ETCHEVERRY, M.; FARNOCHI, C.; TORRES, A ; RIZZO, I.; VARSAVSKY, E. Incidence of aflatoxin, zearalenone, and deoxynivalenol on corn in Argentina. Mycotoxin Research, v.5, n.1, p. 9-13, 1989.

CONCON, J.M. Mold and mycotoxin contamination of food products. In: CONCON, J.M. Food toxicology: contaminants and additives, parte B. New York: Marcel Dekker, 1988. cap. 13, p. 677-770.

DIENER, U.L.; COLE, R.J.; SANDERS, T.H.; PAYNE, G.A.; LEE, L.S.; KLICH, M.A. Epidemiology of aflatoxin formation by Aspergillus flavus. Annual Review Phytopathology, n. 54, p. 249-270, 1987.

DIENER, U.L.; DAVIS, N.D. Aflatoxin production by isolates of Aspergillus flavus. Phytopathology, v. 56, p. 1390-1393, 1966.

DIENER, U.L.; DAVIS, N.D. Aflatoxin formation by Aspergillus flavus. in: GOLDBLATT, L.A Aflatoxin: scientific background, control, and implications. New York: Academic Press, 1969. cap 2, p. 13-54. 
ECHANDI, R. The relationship between aflatoxin formation and kernel damage in Costa Rica maize. In: ZUBER, M.S.; LILLEHOJ, E.B.; RENFRO, B.L. (Eds). Aflatoxin in maize: a proceedings of the workshop. El Battan, CIMMYT, 1986. p. 164-171.

ELLIS, W.O.; SMITH, J.P.; SIMPSON, B.K.; OLDHAM, J.H. Aflatoxins in Food: Occurrence, Biosynthesis, Effects on Organisms, Detection, and Methods of Control. Critical Reviews in Food Science and Nutrition. v. 30, n.4, p.403439, 1991.

FAO. El maiz: en la nutrición humana. Roma: 1993a. 172 p. (Coleción FAO: Alimentación e Nutrición, 25).

FAO QUARTERLY BULLETIN OF STATISTICS, v. 8, n. 3/4, p. 48, 1995.

FAO. Sampling plans for aflatoxin analysis in peanuts and corn. Roma: 1993b. 75 p. (FAO: Food and Nutrition Paper, 55).

FENNEL, D.I. Aspergillus flavus and other fungi associated with insect-damage field corn. Cereal Chemistry, v. 52, May-June 1975, p. 314-321.

FONSECA, H. Contribuiçăo ao estudo da ocorrência de aflatoxina em tortas, farelos e farinhas de amendoim (Arachis hypogaea L.) no Estado de São Paulo. Piracicaba, 1968. 65 p. Tese (Doutorado) - Escola Superior de Agricultura "Luiz de Queiroz", Universidade de São Paulo.

FONSECA, H. Micotoxinas em milho. In: FANCELLI, L.A.; DOURADO NETO, D. (Ed) Tecnologia da produção de milho. Piracicaba, 1997. p.10-17. 
FONSECA, H.; NOGUEIRA, J.N.; GRANER, M.; OLIVEIRA, A.J.; CARUSO, J.G.B.; BORALLI, M.A.; CALORI, M.A.; KHATOUNIAN, C.A. Natural occurrence of mycotoxins in some Brazilian foods. In: INTERNATIONAL IUPAC SYMPOSIUM ON MYCOTOXIN AND PHICOTOXINS, 5. , Viena, 1982. Proceedings. Viena: World Health Organization, 1982. p.76-79.

FONSECA, H.; NOGUEIRA, J.N.; GRANER, M.; OLIVEIRA, A.J.; CARUSO, J.G.B.; BORALLI, M.A.; CALORI, M.A.; KHATOUNIAN, C.A. Natural occurrence of mycotoxins in some Brazilian foods. Part II. In: WORLD CONGRESS OF FOOD SCIENCE AND TECHNOLOGY, 6., Dublin, 1983. Proceedings. Dublin: Boole Press, 1983. p. 53-54.

FRISVAD, J.C.; THRANE, U. Mycotoxin production by food-borne fungi. In: SAMSOM, R.A.; HOEKSTRA, E.S.; FRISVAD, J.C.; FILTERBORG, 0. Introduction to food-borne fungi. Netherlands: CBS, 1996. cap 4, p.251260.

GLÓRIA, E. M; FONSECA, H.; SOUZA, I.M. Occurrence of mycotoxins in maize delivered to the food industry in Brazil. Tropical Science, v. 37, p. 107-110, 1997.

GOLDBLATT, L.A. Aflatoxin: scientific background, control, and implications. New York: Academic Press, 1969. p. 1-11: Introduction.

GOLDBLATT, L.A. Control and removal of aflatoxin. Journal of the American Oil Chemists'Society, v. 48, p. 605-609, 1971. 
HARTLEY, R.D.; NESBITT, B.F.; O'KELLY, J. Toxic metabolites of Arpergillus flavus. Nature, v.198, n.4885, p.1056-1058. 1963.

HAYES, A.W.; DAVIS, N.D.; DIENER, U.L. Effect of aeration on growth and aflatoxin production by Aspergillus flavus in submerged culture. Applied Microbiology, n. 14, p. 1019-1021, 1966.

HEATHCOTE, J.G. Aflatoxins and related toxins. In: BETINA, V. (Ed.) Mycotoxins: production, isolation, separation and purification. Amsterdam: Elsevier, 1984. p. 89-130.

HEATHCOTE, J.G; HIBBERT, J.R. Aflatoxins: chemical and biological aspects. Amsterdam: Elsevier, 1978. p. 173-186: Control of aflatoxins.

HESSELTINE, C.W.; ROGERS, R.F.; SHOTWELL, O.L. Aflatoxin and mold flora in North Carolina in 1977 corn crop . Mycologia, n. 73, p. 216-228, 1981.

HESSELTINE, C.W.; SHOTWELL, O.E.; KWOLEK, W.F.; LILLEHOJ, E.J.; JACKSON, W.K.; BOTHAST, R.J. Aflatoxin occurrence in 1973 corn at harvest II. Mycological studies. Mycologia, v. 68, p. 341-353, 1976.

HSIEH, D.P.H. The role of the aflatoxin in human cancer. In: STEYN, P.S.; VLEGGAAR, R. (Ed). Mycotoxins and Phycotoxins. Amsterdam: Elsevier, 1986. p. $447-454$. 
HSIEH, D.P.H. Potencial human health hazards of mycotoxins. In: INTERNATIONAL IUPAC SYMPOSIUM ON MYCOTOXINS AND PHYCOTOXINS, 7., Tokyo, 1988. Mycotoxins and phycotoxins' 88: proceedings. Amsterdan: Elsevier Science, 1989. P. 69-80. (Bioactive Molecules, 10).

HSIEH, D.P.H.; WONG, Z.A.; WONG, J.M.; HICHAS, C.; RUEBNER, B.H. Comparative Metabolism of Aflatoxin. In: RODRICKS, J.V.;.HESSELTINE, C.W.; MEHLMAN, M.A. (Ed). Mycotoxins in human and animal health. Park Forest: South: Pathotox., 1977. p. 37-50.

JOHNSON, R.M.; GREENAWAY, W.T.; DOLAN, W.P. Estimation of aflatoxin in corn by "dockage" assay. Journal of the Association of Official Analitycal Chemists, v.52, n.6, p. 1304-1306, 1969.

KROGH, P. Occurrence of mycotoxins in food. In: KROGH, P. Mycotoxins in food. London: Academic Press, 1987. p. 97-121.

LEE, L.S.; LILLEHOJ, E.B.; KWOLEK, W.F. Aflatoxin distribution in individual corn kernels from intact ears. Cereal Chemistry, v.57, n.5, p.340-343. 1980.

LILLEHOJ, E.B.; FENNEL, D.I. Fungi and aflatoxin in a bin of stored white maize. Journal of Stored Products Research, v. 11, p. 47-51, 1975.

LILLEHOJ, E.B.; HESSELTINE, C.W. Aflatoxin control during plant growth and harvest of corn. In: RODRICKS, J. (Ed). Mycotoxins in human and animal health. Park Forest South: Pathotox ., 1977, p. 107-120. 
MACHADO, A.A.; ZONTA, H.P. Manual do usuário do sistema de análise estatística para microcomputadores, versão 2.1. 1990.

MARASAS, W.F.O.; NELSON, P.E. Mycothoxicology: introduction to the mycology, plant pathology, chemistry, toxicology, and pathology of naturally occurring mycotoxicoses in animals and man. The Pennsylvania State University Press, 1987. p. 25-31: Aflatoxicosis.

MCMILLIAN, W.W. Relation of insects to aflatoxin contamination in maize grown in the Southeastern USA. In: ZUBER, M.S.; LILLEHOJ, E.B.; RENFRO, B.L. (Eds). Aflatoxin in maize: a proceedings of the workshop. El Batan, CIMMYT, 1986. p. 194-200.

MEINDERS, B.L.; HURBURG Jr., C.R. Properties of corn screenings. Transactions of the ASAE, v. 36, n.3, p. 811-819, May-June 1993.

MENEGAZZO, R.; LAZZARI, F.A. Micotoxinas em milho para rações, na região sul do Brasil. In: CONGRESSO NACIONAL DE MILHO E SORGO, 21., Londrina, 1996. Resumos. Londrina: ABMS, 1996, p.341.

MILNER, M.; GEDDES, W.F. Respiration and heating. In: ANDERSON, J.A.; ALCOCK, A.W. (Eds). Storage of cereal grains and their products. St. Paul: American Association of Cereal Chemists, 1954. cap. 4, p. 152-220.

MOSS, M.O.; SMITH, J.E. Mycotoxins: formation, analysis and significance. Chinchester: John Wiley \& Sons, 1985. 148p.

MYCOTOXINS; economic and health risks. Ames: Council for Agricultural Science and Technology, 1989. 91p. (Task Force Report, 116). 
OZAY, G.; HEPERKAN, D. Mould and mycotoxin contamination of stored corn in Turkey. Mycotoxin Research, v.5, n.2, p.81-89, 1989.

PALMGREN, M.S.; HAYES, A.W. Aflatoxins in food. In: KROGH, P.(Ed). Mycotoxins in food. London: Academic Press, 1987. cap 4. p. 65-95.

PARK, D.L.; STOLOFF, L. Aflatoxin control how a regulatory agency managed risk from unavoidable natural tixicant in food and feed. Regulatory Toxicology and Pharmacology, v.9, p. 109-130, 1989.

PUZZI, D. Abastecimento e armazenagem de grãos. Campinas: Instituto Campineiro de Ensino Agrícola, 1986, 341 p.

QASEM, S.A.; CHRISTENSEN, C.L. Influence of moisture content, temperature, and time on deterioration of stored corn by fungi. Phytopathology, v. 48, p. 544-549, 1958.

QASEM, S.A.; CHRISTENSEN, C.L. Influence of various factors on the deterioration of stored corn by fungi. Phytopathology, v. 50, p. 703-709, 1960.

RAMBO, G.D.; TUITE, J.; CALDWELL, R.W. Aspergillus flavus and aflatoxin in preharvest corn from Indiana in 1971 and 1972. Cereal Chemistry, v. 51, p. 848-853, 1974.

RESNIK, S.; NEIRA, S.; PACIN, A.; MARTINEZ, E.; APROS, N.; LATREIRE, S. A survey of the natural occurrence of aflatoxins and zearalenone in Argentine field maize: 1983-1994. Food Additives and Contaminants, v. 13, n. 1, p. 115-120, 1996. 
RODRICKS , J.V.; STOLOFF, L. Aflatoxin residues from contaminated feed edible tissues of food-producing animals. In: RODRICKS, J.V.; HESSELTINE, C.W.; MEHLMAN, M.A. (Eds). Mycotoxins in human and animal health. Park Forest South: Pathotox, 1977, p. 67-79.

ROEBUCK, B.D.; MAXITENKO, Y.Y. Biochemical mechanisms and biological implications of the toxicity of aflatoxins as related to aflatoxin carcinogenesis. In: EATON, D.L.; GROOPMAN, J.D. The toxicology of aflatoxins: human health, veterinary and agricultural significance. San Diego: Academic Press, 1994. cap.2, p. $27-43$.

SABINO, M.; PRADO, G.; INOMATA, E.I.; PEDROSO, M.O.; GARCIA, R.V. Ocorrência natural de aflatoxinas e zearalenona em milho no Brasil - II Parte. In: ENCONTRO NACIONAL DE MICOTOXINAS 5., São Paulo, 1988. Resumos. São Paulo: Sociedade Brasileira de Microbiologia, 1988. p. 21

SANTURIO, J.M.; MALLMANN, C.A.; BALDISSERA, M.A.; MAIXNER, A.E.; MONTAGNER, S.T.; GOULART, K.; SANO, R. Prevalência e sazonalidade de mocotoxinas em commodities e rações no Sul do Brasil. In: CONGRESSO LATINOAMERICANO DE MICOTOXICOLOGIA, 2., Maracay, 1997; CONGRESSO LATINOAMERICANO DE AVICULTURA, 14., Cancún, 1997. Resumo. Maracay: Quinabra, 1997.p. 24.

SAUER, D.B.; MERONUCK, R.A.; CHRISTENSEN, C.M. Microflora. In: SAUER, D.B. (Ed). Storage of cereal grains and their products. St. Paul: American Association of Cereal Chemists, 1992. p. 313-340. 
SCHINDLER, A.F.; PALMER, J.G.; EISENBERG, W.V. Aflatoxin production by Aspergillus flavus as related to various temperatures. Applied Microbiology, v. 15, n. 5, p. 1006-1009, 1967.

SCHROEDER, H.W.; HEIN Jr., H. Aflatoxins: production of the toxins in vitro in relation to temperature. Applied Microbiology, v. 15, n. 2, p. 441-445, 1967.

SCOTT, P.M. Mycotoxin Methodology. In: INTERNATIONAL IUPAC SYMPOSIUM ON MYCOTOXINS AND PHYCOTOXINS, 8 , México, 1992. Proceedings. México: National Anthropology Museum, 1992. p.52-53.

SCOTT, P.M. Natural poisons. In: ASSOCIATION OF OFFICIAL ANALYTICAL CHEMISTS. Official methods of analysis. 15.ed. Arlington, 1990. cap. 49, p. 1184-1213.

SEITZ, L.M.; SAUER, D.B.; MOHR, H.E. Storage of high-moisture corn: fungal growth and dry matter loss. Cereal Chemistry, v. 59, n. 2, p. 100-105, 1982.

SÉTAMOU, M.; CARDWELL, K.F.; SCHUTHESS, F.; HELL, K. Aspergillus flavus infection and aflatoxin contamination of preharvest infection and aflatoxin contamination of preharvest maize in Benin. Plant Disease, v. 81, $n$. 11, p. $1323-1327,1997$.

SHANK, R. Mycotoxicoses of man: dietary and epidemiological conditions. In: WYLLIE, T.D.; MOREHOUSE, L (Ed). Mycotoxic fungi: mycotoxins, mycotoxicoses. New York: Marcel Dekker, 1978. v.3, p. 1-15. 
SHOTWELL, O.L.; GOULDEN, M.L.; HESSELTINE, C.W. Aflatoxin contamination: association with foreign material and characteristic fluorescence in damaged corn kernels. Cereal Chemistry, v.49, n.4, p. 458465, July/Aug. 1972.

SHOTWELL, O.L.; GOULDEN, M.L.; HESSELTINE, C.W. Aflatoxin: distribution in contaminated corn. Cereal Chemistry, v.51, n.4, p.492-499, May/June 1974.

SHOTWELL, O.L.; GOULDEN, M.L.; LILLEHOJ, E.B.; KWOLEK, W.F.; HESSELTINE, C.W. Aflatoxin occurrence in 1973 corn at harvest. III. Aflatoxin distribution in contaminated, insect-damaged corn. Cereal Chemistry, v.54, n.3, p.620-626, May/June, 1975.

SMITH, J.E.; MOSS, M.O. Mycotoxins: formation, analysis, and significance. Chichester: John Wiley \& Sons, 1985. cap. 6: Natural occurrence of mycotoxins, p. 83-103.

SOARES, L.M.V.; RODRIGUEZ-AMAYA, D.B. Survey of aflatoxins, ochratoxin A, zearalenone and sterigmatocystin in some Brazilian food by using multitoxin thin-layer chromatographic method. Journal of the Association of Official Analytical Chemsts, v.72, p.22-26, 1989.

STARK, A. Molecular aspects of aflatoxin $\mathrm{B}_{1}$ mutagenesis and carcinogenesis. In: STEYN, P.S.; VLEGGAAR, R. Mycotoxins and Phycotoxins. Amsterdam: Elsevier Science., 1986. v.1, p. 435-445. 
STEELE, J.L.; SAUL, R.A.; HUKILL, W.V. Deterioration of shelled corn as measured by carbon dioxide production. Transactions of the ASAE, n.68, n.621, p.685-689, 1969.

STEVENS, A.,J.; SAUNDERS, C.N.; SPENCE, J.B.; NEWHAM, A.G. Investigations into "deseases of turkey poults. Veterinary Records., v.72, n. 31, p.627-628. 1960.

STOLOFF, L. Aflatoxin: a overview. In: RODRICKS, J.V.; HESSELTINE, C.W.; MEHLMAN, M.A. Mycotoxins in human and animal health. Park Forest South: Pathotox, 1977. cap. 1, p. 7-28.

STROSHINE, R.L.; YANG, X. Effects of hybrid and grain damage on estimated dry matter loss for high-moisture shelled corn. Transactions of the ASAE, v.33, n.4, p.1291-1298. 1990.

SYLOS, C.M.; RODRIGUEZ-AMAYA, D.B.; SANTURIO, J.M.; BALDISSERA, M.A. Occurrence of aflatoxins and cyclopiazonic acid in Brazilian peanut and corn. In: INTERNATIONAL IUPAC SYMPOSIUM ON MYCOTOXINS AND PHYCOTOXINS 9., Rome, 1996. Abstract book. Rome: Istituto Superiore di Sanità, 1996, p. 132.

TRUCKSESS, M.W.; STOLOFF, L.; MISLIVEC, P.B. Effect of temperature, water activity and other toxigenic mould species on growth of Aspergillus flavus and aflatoxin production on corn, pinto beans and soybeans. Journal of Food Protection, Ames, n.51, v.5, p.361-363, 1988. 
TUITE, J.; KOH-KNOX, C.; STROSHINE, R.; CANTONE, F.A.; BAUMAN, L.F. Effect of physical damage to corn kernels on development of Penicillium species and Aspergillus glaucus in storage. Phytopathology, v. 75, n.10, p. 1137-1140, 1985.

TURMO, E Syntesis and mutagenicity of afltoxin $\mathrm{B}_{1}$ model $3 a, 8 \mathrm{a}$-dihidro4,6,dimmmethyoxyfuro (2,3-b) benzofuran and its 2,3 epoxy derivative. Journal of Agriculture and Food Chemistry, n. 39, p. 1723-1728, 1991.

WIN, R.T.; LANE, G.T. Aflatoxin production on high moisture corn and sorghum with a limited incubation. Journal of Dairy Science, n. 61, p. 762-764, 1978.

WOOD, G.E. Mycotoxins in foods and feeds in the United States. Journal of Animal Science, v.70, n.12, p.3941-3949, 1992.

WORLD HEALTH ORGANIZATION. Mycotoxins. Geneva, 1979. 127 p. (Environmental Health Criteria).

ZUBER, M.S.; DARRAH, L.L.; LILLEHOJ, E.B. International survey on natural aflatoxin occurrence in maize. In: ZUBER, M.S.; LILLEHOJ, E.B.; RENFRO, B.L. (Eds). Aflatoxin in maize: a proceedings of the workshop. El Batan, CIMMYT, 1986. p. 285-288. 